\title{
基于二茂铁的金属阳离子识别受体的研究进展
}

\author{
刘玉婷* 李 洁 尹大伟
}

(陕西科技大学化学与化工学院 陕西省轻化工助剂重点实验室 西安 710021)

\begin{abstract}
摘要 由于工业的迅速发展，水体中的金属离子的浓度大幅度地增大，从而引起了一系列的危害. 因此，离子识别受 体和电化学传感器的研究深受科研人员的青棟. 二茂铁具有稳定的氧化还原性能和易于化学修饰等特点，同时二茂铁 衍生物的合成方法非常成熟，从而成为了一类非常重要的金属阳离子识别受体. 按冠醚、多胺、共轭及杂环等不同分 子识别中心进行分类，从所用原料、合成方法、分子结构等方面，就近几年基于二茂铁的金属阳离子识别受体的研究 进展进行了综述，同时对其前景及发展进行了展望.
\end{abstract}

关键词 二茂铁; 阳离子识别; 受体; 研究进展

\section{Progress of Ferrocene-Based Metal Cation Recognition Receptor}

\author{
Liu, Yuting* Li, Jie Yin, Dawei \\ (Shaanxi Key Laboratory of Chemical Additives for Industry, College of Chemistry and Chemical Engineering, \\ Shaanxi University of Science \&Technology, Xi'an 710021)
}

\begin{abstract}
Due to the rapid development of industry, the concentration of metal ions in water has increased significantly, thus causing a series of harm. Therefore, the research on ion recognition receptors and electrochemical sensors is favored by researchers. Ferrocene based metal compounds are considered to be very important metal cation recognition receptors due to their stability, favourable electrochemical property, reaction activity, and the synthesis method of ferrocene derivatives is very mature. From the aspects of raw materials, synthesis methods, molecular structure, etc., the research progress of ferro-cene-based cation recognition receptors in recent years is reviewed. It is mainly classified from different molecular recognition centers such as crown ethers, polyamines, conjugates and heterocycles. At last, the future and development of ferrocene receptors are prospected.
\end{abstract}

Keywords ferrocene; cation recognition; receptor; research progress

1951 年, Pauson 等成功合成了二茂铁之后, 二茂铁 及其衍生物的合成及应用引起了广泛的关注 ${ }^{[1-5]}$. 二茂 铁是一种夹心型结构的芳香性分子, 不仅具有良好的电 化学和光化学性质, 而且具有氧化还原性、高耐受性、

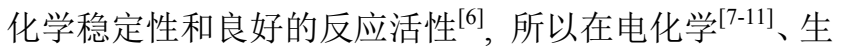

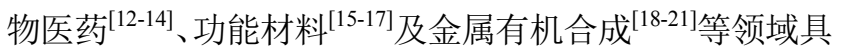
有广泛的应用. 研究发现, 二茂铁衍生物还可以提高生 物相容性, 表现出良好的抗癌活性, 具有较高的临床应 用价值 ${ }^{[22]}$. 金属离子在自然环境中分布广泛, 在生命体 代谢过程中起着重要作用, 同时, 环境及食品引起人体 内过渡金属及重金属离子过量, 会导致肿瘤和癌症等的 发生 ${ }^{[23-25]}$, 因此对金属离子进行定量分析是至关重要的.
基于金属阳离子在生物代谢过程、环境检测和临床医学 中的潜在应用，设计合成对其具有高选择性和高灵敏度 的识别受体分子的研究深受科研工作者的青睐 ${ }^{[26-29]}$.

二茂铁及其衍生物因具有稳定的氧化还原活性和 易化学修饰等特点, 在电化学金属离子化学传感器中具 有重要的地位 ${ }^{[30-31]}$. 在二茂铁化学传感器中, 二茂铁基 作为电信号响应单元, 利用受体与金属阳离子络合后导 致氧化还原电位发生变化达到识别的效果. 此外, 二茂 铁衍生物与所识别阳离子结合后, 其分子内的光电结构 发生改变, 使得其紫外吸收峰红移或蓝移, 分子苂光效 应增强或减弱，从而达到识别离子 ${ }^{[32-34]}$. 本文按冠醚、 多胺、共轭及杂环等不同分子识别中心进行分类, 对以

\footnotetext{
* Corresponding author. E-mail: 1yt@sust.edu.cn

Received May 18, 2020; revised June 28, 2020; published online August 11, 2020.

Project supported by the National Natural Science Foundation of China (No. 201706152), the Shaanxi Natural Science Basic Research Program (General) (No. 2018JM7046) and the Special Scientific Research of Shaanxi Provincial Department of Education (No. 18JK0954).

国家自然科学基金(No. 201706152)、陕西省自然科学基础研究计划(面上)(No. 2018JM7046)、陕西省教育厅专项科研(No. 18JK0954)资助项目.
} 
二茂铁为电化学活性中心的二茂铁阳离子识别受体的 设计、合成及结构进行了综述，并对其应用前景进行了 展望.

\section{1 二茂铁冠醚类受体}

20 世纪 60 年代, Pedersen ${ }^{[35]}$ 首次合成了由环或多环 组成的冠醚分子, 并发现冠醚对金属离子具有选择性识 别功能, 其相应的配合物是由冠醚上的氧原子和金属阳 离子相互作用形成. 随之, 氧杂、氮杂等冠醚也相继问 世, 该类基团可以与金属离子以氢键等作用进行配位. 同时冠醚环的大小影响着配合物的稳定性, 阳离子大小 和冠醚环空腔大小越接近, 配合物越稳定 ${ }^{[36-40]}$. 目前, 对于以二茂铁基为电化学活性中心的冠醚类受体, 可以 通过光学方法、电化学方法及核磁共振谱图等方法证明 其对金属阳离子的识别 ${ }^{[41-43]}$.

2008 年, 徐伟娜 ${ }^{[44]}$ 将对甲苯磺酸酯依次与 $\mathrm{NaN}_{3}$ 和 $1,1^{\prime}$-二茂铁二甲酸反应得到二茂铁桥联多醚叠氮化物 $1 \mathrm{a}$ 和 $1 \mathrm{~b}$, 再与二茂铁乙炔通过 $\mathrm{Cu}(\mathrm{I})$ 催化的叠氮一炔基 环加成反应设计合成了二茂铁开链冠醚受体 2 和 3 (Scheme 1), 受体 2 和 3 可以有效识别 $\mathrm{CH}_{2} \mathrm{Cl}_{2} / \mathrm{CH}_{3} \mathrm{CN}$ $(V: V=1: 1)$ 溶液中的 $\mathrm{Mg}^{2+}$. 一般情况下, 二茂铁受 体与阳离子作用后, 氧化还原电位由于静电排斥通常会 向阳极移动, 而化合物 2 和 3 与 $\mathrm{Mg}^{2+}$ 配位后, 其氧化还 原电位向阴极移动. 作者推测可能是化合物中的羰基使 得铁核周围的电子云密度增大所致.
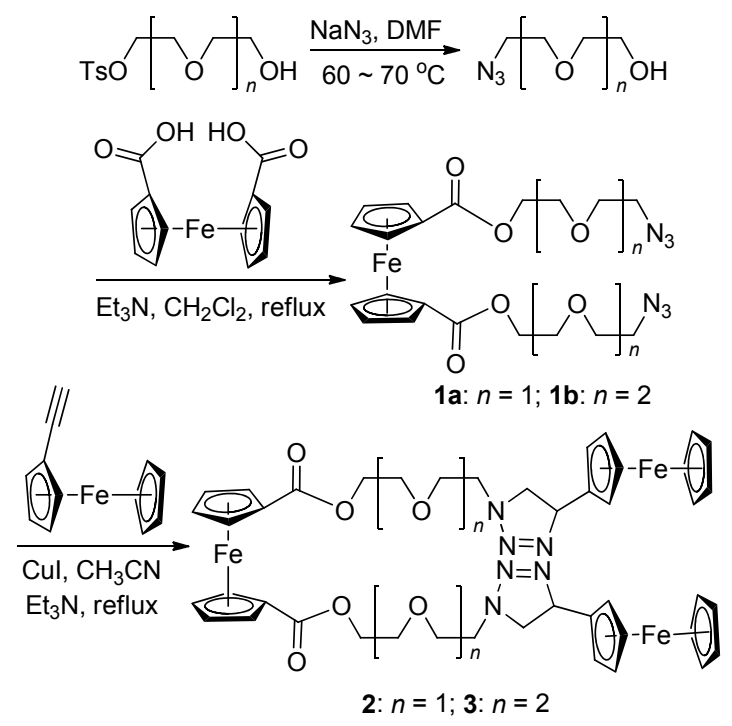

图式 1 二茂铁基受体 2 和 3 的合成

Scheme 1 Synthesis of ferrocenyl receptors $\mathbf{2}$ and $\mathbf{3}$

2009 年, 胡玲 ${ }^{[45]}$ 用硫杂杯 [4]芳烃与多甘醇碘代物 4 经回流反应生成硝基化合物 5, 5 还原得到相应的胺 $\mathbf{6}$, 再与二茂铁甲酰氯反应，生成了由不同长度多醚链连接 的二茂铁酰胺受体 7 和 8 (Scheme 2). 紫外谱图显示, 在 $\mathrm{CH}_{2} \mathrm{Cl}_{2} / \mathrm{CH}_{3} \mathrm{CN}(\mathrm{V}: V=1: 1)$ 溶液中, 随着 $\mathrm{Eu}^{3+}$ 的加入 化合物 7 和 8 在 $444 \mathrm{~nm}$ 处的吸收峰强度逐渐加强, 同时 溶液颜色明显加深, 由橙色变为棕黄色. 此外, 化合物 7 和 8 均与 $\mathrm{Eu}^{3+}$ 形成 $1: 2$ 型配合物.
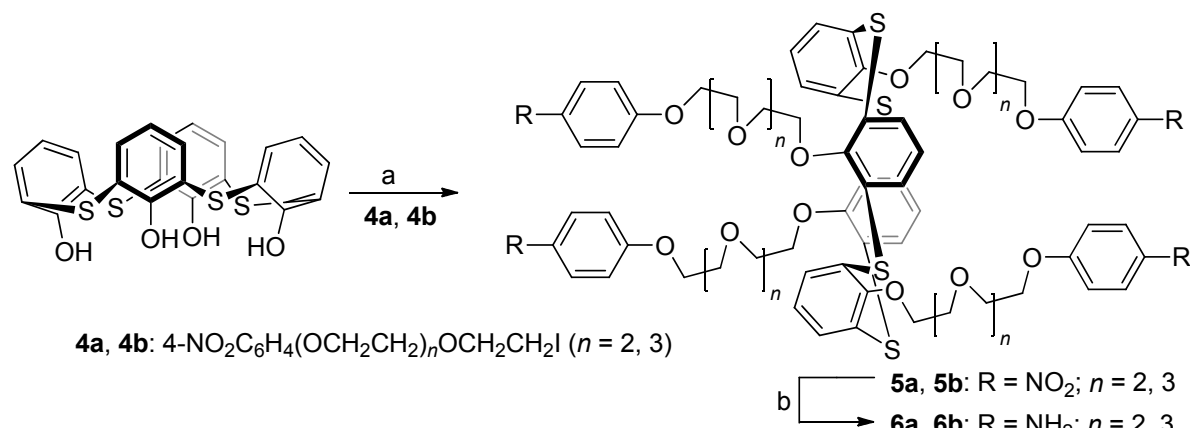

4a, 4b: 4- $\mathrm{NO}_{2} \mathrm{C}_{6} \mathrm{H}_{4}\left(\mathrm{OCH}_{2} \mathrm{CH}_{2}\right)_{n} \mathrm{OCH}_{2} \mathrm{CH}_{2} \mathrm{I}(n=2,3)$

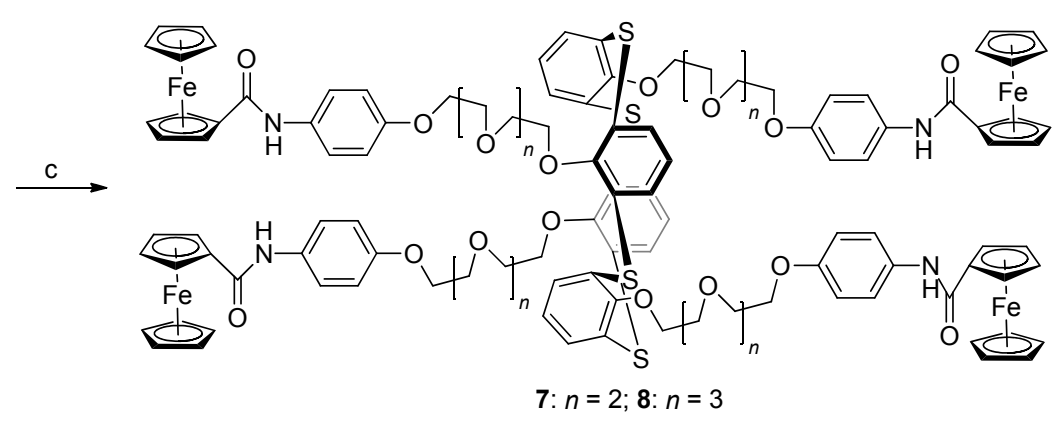

Reagents and conditions: (a) $\mathrm{Cs}_{2} \mathrm{CO}_{3}, \mathrm{CH}_{3} \mathrm{CN}$, reflux; (b) active-C, $\mathrm{FeCl}_{3} \cdot 6 \mathrm{H}_{2} \mathrm{O}, \mathrm{NH}_{2} \mathrm{NH}_{2} \cdot \mathrm{H}_{2} \mathrm{O}$, ethanol, reflux; (c) chlorocarbonylferrocene, $\mathrm{CH}_{2} \mathrm{Cl}_{2}$, r.t.

图式 2 二茂铁基受体 7 和 8 的合成

Scheme 2 Synthesis of ferrocenyl receptors 7 and $\mathbf{8}$ 
2010 年, 洪碧琼 ${ }^{[46]}$ 将杯 [4]芳烃-1,3-二乙酸乙酯衍 生物与水合肼反应, 再与二茂铁甲醛缩合形成 Schiff碱, 即含二茂铁基的杯 [4]芳烃衍生物 9 (Scheme 3). 化合物 9 可以选择性识别有机相中的 $\mathrm{Eu}^{3+}, \mathrm{Cu}^{2+}, \mathrm{Zn}^{2+}$ 和 $\mathrm{Ba}^{2+}$ 等金属离子, 其中对 $\mathrm{Eu}^{3+}$ 的电化学响应效果最佳, 其主要氧化波的半波电位负移 $712 \mathrm{mV}$. 这是因为 $\mathrm{Eu}^{3+}$ 的电荷数高, 体积适中, 且具有良好的匹配性.

2012 年, 张丽静 ${ }^{\left[{ }^{2}\right]}$ 以硫杂杯 $[4]$ 芳烃双叠氮化物为 原料, 以 $\mathrm{CuI}$ 为催化剂, 与二茂铁乙炔在四氢呋喃 $(\mathrm{THF}) / \mathrm{H}_{2} \mathrm{O}$ 混合溶剂中进行 CuAAC 反应合成了硫杂杯
[4]芳烃开链冠醚受体 10 (Scheme 4). 紫外光谱图显示, 在 $\mathrm{CH}_{2} \mathrm{Cl}_{2} / \mathrm{CH}_{3} \mathrm{CN}(V: V=1: 1)$ 溶液中, 化合物 $\mathbf{1 0}$ 与 $\mathrm{Co}^{2+}$ 和 $\mathrm{Cu}^{2+}$ 作用后, 其紫外吸收光谱发生显著变化; 电 化学实验表明, 当加入 $\mathrm{Ca}^{2+}, \mathrm{Cu}^{2+}, \mathrm{Cd}^{2+}, \mathrm{Pb}^{2+}$ 和 $\mathrm{Hg}^{2+}$ 离 子时, 其循环伏安图中半波电位发生明显移动.

2015 年, Dagdevren 等 ${ }^{[48]}$ 采用二茂铁取代的环丁烯 酮 11 与锂苯并冠醚反应, 再与对苯二酚经热重排及空 气氧化，制备了一种新型二茂铁菜醌冠醚化合物 12 (Scheme 5). 紫外-可见分光光度滴定实验表明, 化合物 12 可以在乙腈溶液中高度选择性识别 $\mathrm{Ba}^{2+}$ 和 $\mathrm{Ca}^{2+}$. 作

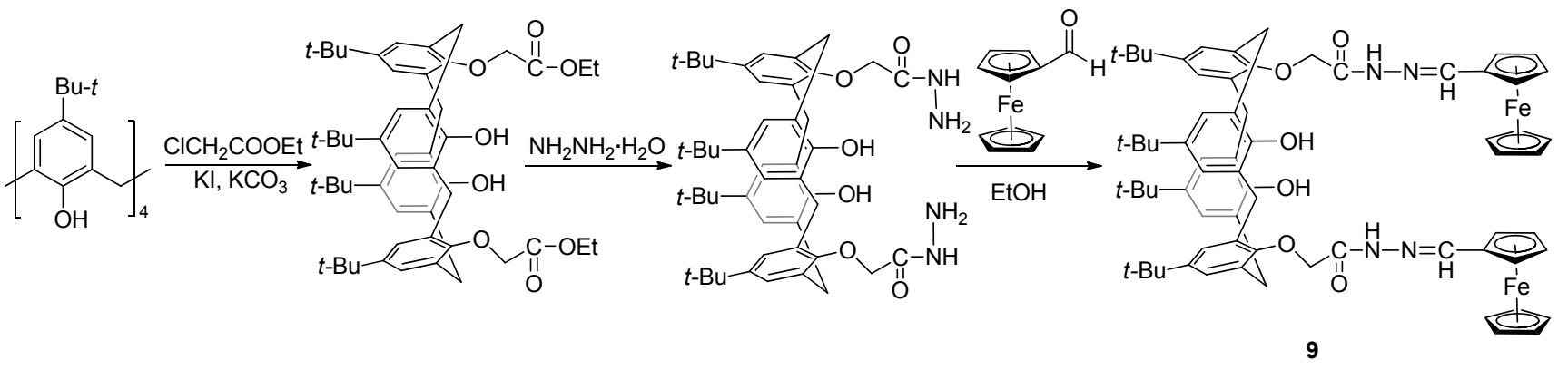

图式 3 二茂铁基受体 9 的合成

Scheme 3 Synthesis of ferrocenyl receptor 9

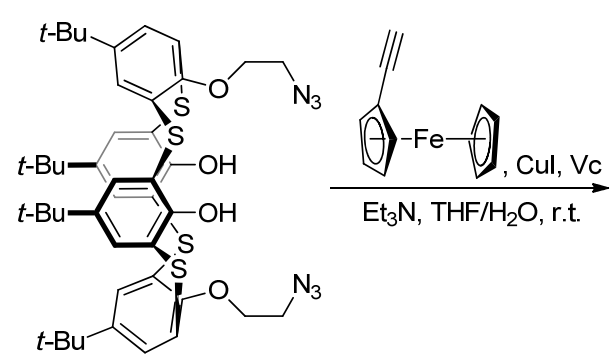

图式 4 二茂铁基受体 10 的合成

Scheme 4 Synthesis of ferrocenyl receptor 10

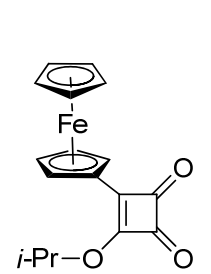

11
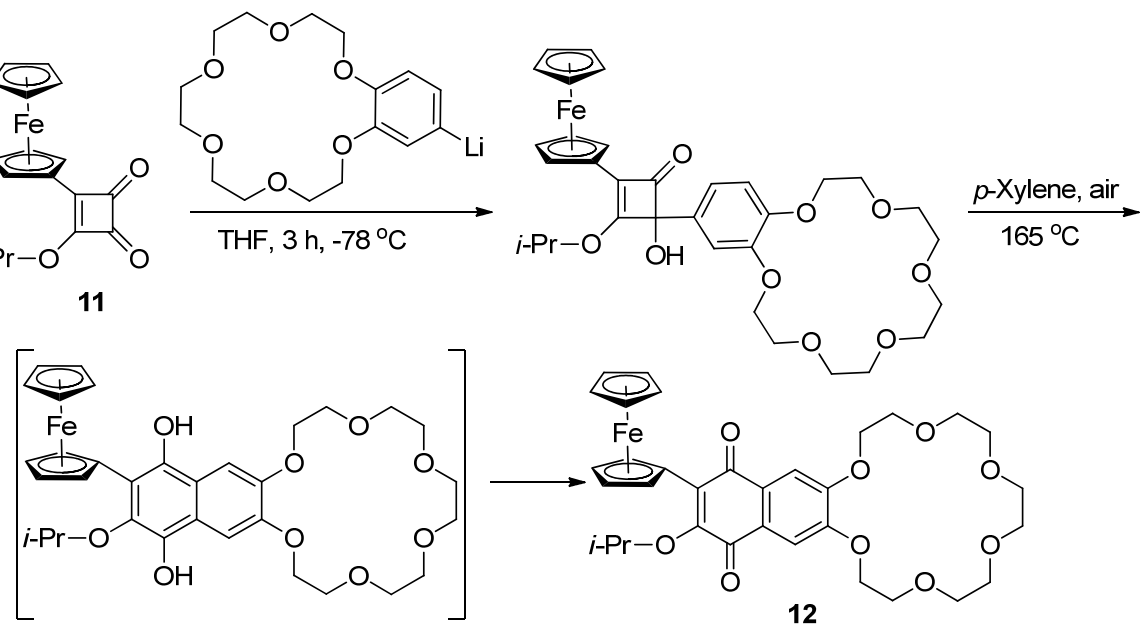<smiles>CCCCOc1cc2c(C(=O)C(=C(OC(C)C)C(=O)c3ccccc3)c3ccccc3)cc1OCCOCCOCCOCCOCCO2</smiles>

图式 5 二茂铁基受体 12 的合成

Scheme 5 Synthesis of ferrocenyl receptor 12 
者还提出, 受体 12 结构中的二茂铁和菜醌之间的分子 内电荷转移跃迁是 $\mathbf{1 2}$ 选择性结合的主要机制. 2018 年, Alcay 等 ${ }^{[49]}$ 采用同样的方法设计合成了两种新型二茂铁 冠醚化合物 13 和 14. 在 $N, N$-二甲基甲酰胺(DMF)溶液 中, 随着 $\mathrm{Be}^{2+}$ 的加入化合物 13 和 14 的紫外光谱图发生 显著变化, 同时溶液颜色从深绿色变成黄色, 可以达到 裸眼识别.
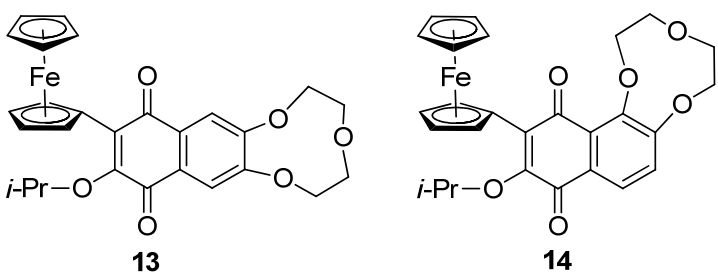

2017 年, Flores 等 ${ }^{[50]}$ 以二茂铁甲醛 15 和 4-氨基苯 并-15-冠-5 为原料设计合成了一种新型二茂铁冠醚化合 物 16 (Scheme 6), 其可以在 $\mathrm{Pb}^{2+}$ 和 $\mathrm{Fe}^{3+}$ 等竞争性离子的 存在下高选择性识别 $\mathrm{Cu}^{2+}$. 电化学实验结果显示, 在 pH 6.0 和 6.5 下的缓冲溶液中可以观察到最大电流信号. 在较低的 $\mathrm{pH}$ 值下, 由于大环结构中的氧原子和质子之 间的静电作用导致电流强度较低; 而 $\mathrm{pH}$ 高于 6.5 时会生 成 $\mathrm{CuO}$ 和 $\mathrm{Cu}(\mathrm{OH})_{2}$ 等不溶物, 从而降低了 $\mathrm{Cu}^{2+}$ 的电化 学响应.

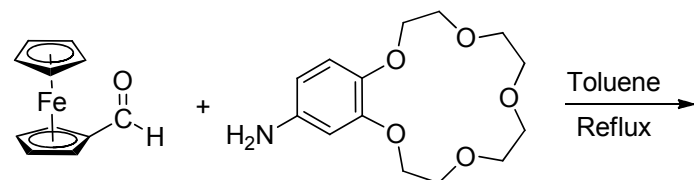

15

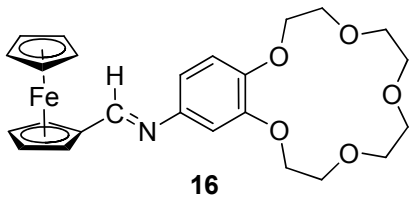

图式 6 二茂铁基受体 16 的合成

Scheme 6 Synthesis of ferrocenyl receptor 16

2019 年, Agurto 等 ${ }^{[51]}$ 报道了一种通过烯烃亚胺间隔 基连接的二茂铁冠醚受体 17 , 其在乙腈溶液中可以选 择性识别 $\mathrm{Cu}^{2+}$. 在 $\mathrm{Cu}^{2+}$ 存在下可以观察到 17 的紫外光 谱图发生了明显变化. 电化学实验表明, 随着 $\mathrm{Cu}^{2+}$ 的加 入亚胺结构及二茂铁基的氧化还原过程的循环伏安曲 线显示出明显的变化, 氧化峰值电流也逐渐减小. 因此, 化合物 17 结构中的亚胺和二茂铁基均参与了 17 与金属 $\mathrm{Cu}^{2+}$ 的络合.

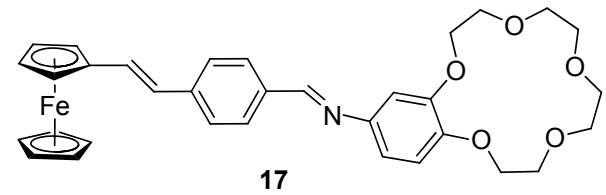

\section{2 二茂铁多胺类受体}

多胺、硫脲、Schiff 碱等配体中含有与金属阳离子 配位能力极佳的氮原子, 其支链上存在含有孤对电子的 氧、硫等杂原子，因此此类化合物被广泛应用于电化学 传感器中 ${ }^{[52-55]}$. 根据文献报道 ${ }^{[56-60]}$, 二茂铁多胺类受体 中的氮原子以及含有的杂原子可以提供孤对电子从而 选择性地与金属离子配位形成金属配合物，使受体分子 的光学或电化学性质发生一定程度的变化，从而有效地 识别金属离子.

2010 年，冯文浩等 ${ }^{[61]}$ 以二茂铁双二氨基硫脲腙和 取代醛为原料, 经取代反应合成了两种新型 1,1'-二取代 二茂铁双二氨基硫艮腙 Schiff 碱 18 和 19 (Scheme 7). 电 化学实验显示, 在 DMF 中化合物 18 和 $\mathrm{Ag}^{+}$有一定程度 的络合, $E_{\mathrm{pa}}$ 正移 $294 \mathrm{mV}$; 而在乙腈中化合物 19 和 $\mathrm{Zn}^{2+}$ 也发生了络合, $E_{\mathrm{pa}}$ 正移 $135 \mathrm{mV}$.

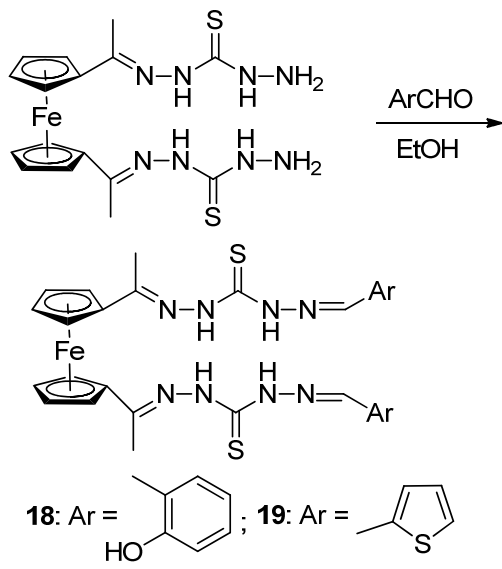

图式 7 二茂铁基受体 18 和 19 的合成

Scheme 7 Synthesis of ferrocenyl receptors 18 and 19

2011 年, Devaraj 等 ${ }^{[62]}$ 通过硫脲和二茂铁乙酰丙酮 缩合合成了两种新型二茂铁受体 20 和 21 (Scheme 8). 紫外光谱显示, 在乙腈中化合物 20, 21 均能高选择性识 别 $\mathrm{Cu}^{2+}$. 加入 $\mathrm{Cu}^{2+}$ 后, 化合物 20 颜色由淡黄色变为绿
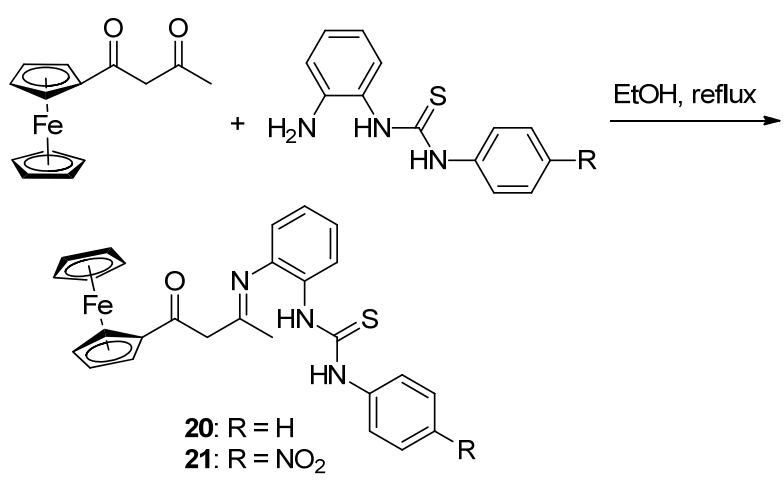

图式 8 二茂铁基受体 20 和 21 的合成 Scheme 8 Synthesis of ferrocenyl receptors $\mathbf{2 0}$ and $\mathbf{2 1}$ 
色, 化合物 $\mathbf{2 1}$ 的颜色由橙色变为深绿色, 可以实现裸眼 识别.

2014 年, Uahengo 等 ${ }^{[63]}$ 通过伯胺与二茂铁甲醛 15 缩合合成了二茂铁基配合物苯二亚胺 22 和联苯二亚胺 23, 其可以选择性识别二甲基亚砜(DMSO)- $\mathrm{H}_{2} \mathrm{O}$ 溶液中 的 $\mathrm{Cu}^{2+}$ 和 $\mathrm{Hg}^{2+}$ (Scheme 9). 通过苂光光谱滴定法研究 发现, $\mathrm{Cu}^{2+}$ 和 $\mathrm{Hg}^{2+}$ 的加入导致所有化合物荧光猝灭, 同 时肉眼可分别检测到从黄色到红色或绿色的显著变化.
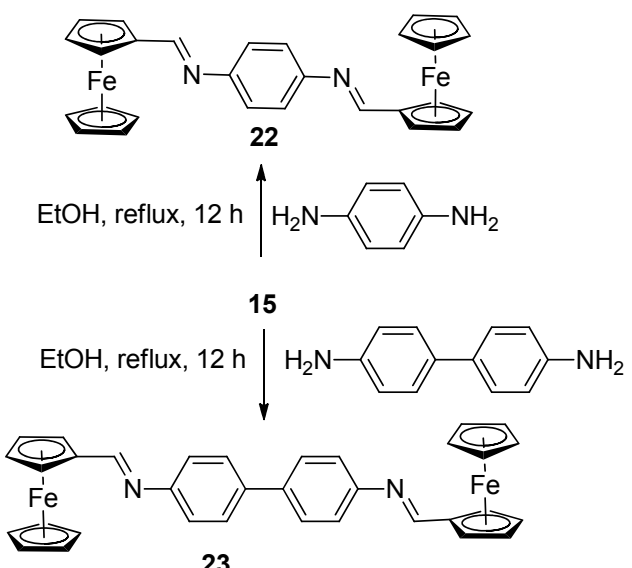

图式 9 二茂铁基受体 22 和 23 的合成

Scheme 9 Synthesis of ferrocenyl receptors 22 and $\mathbf{2 3}$

2015 年, 黄敏等 ${ }^{[64]}$ 以二茂铁(二)甲醛、2,6-二氨基 吡啶和 1,8 -菜啶为原料设计合成二茂铁单臂及双臂衍生 物 24 和 25 (Scheme 10), 其可以选择性识别乙醇溶液中 $\mathrm{Cu}^{2+}$ 和 $\mathrm{Cr}^{3+}$. 通过核磁滴定观察到, 随着 $\mathrm{Cr}^{3+}$ 或 $\mathrm{Cu}^{2+}$ 的 加入, 化合物的化学位移发生移动. 进一步分析表明化 合物 24 吡定 $\alpha$-位的氮及氨基甲酸酯上的氧与 $\mathrm{Cr}^{3+}$ 发生 配位，而 $\mathrm{Cu}^{2+}$ 可能是与吡啶 $\alpha$-位酰胺上的氮配位.

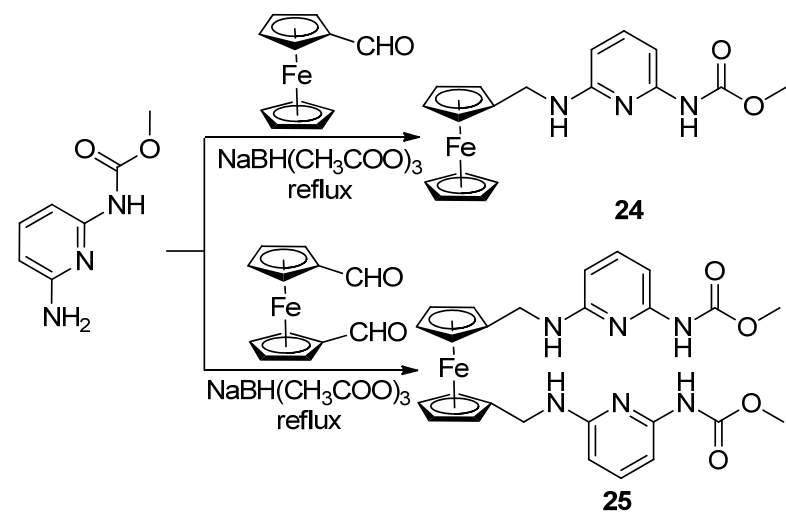

图式 10 二茂铁基受体 24 和 25 的合成

Scheme 10 Synthesis of ferrocenyl receptors 24 and 25

2016 年, 开帅等 ${ }^{[65]}$ 以 $N, N^{\prime}$-二(2-甲基吡啶)苯胺(26) 为原料, 经硝化、还原和缩合反应合成了二茂铁受体 27 (Scheme 11), 通过光谱和电化学法检测, 发现其可以选
择性识别乙腈溶液中的 $\mathrm{Ni}^{2+}$. 此外, 紫外滴定测得化合 物对 $\mathrm{Ni}^{2+}$ 的最低检测浓度分别为 $1 \times 10^{-5} \mathrm{~mol} / \mathrm{L}, \mathrm{Job}$ 法 测出受体 27 与 $\mathrm{Ni}^{2+}$ 形成 $1: 1$ 络合物.

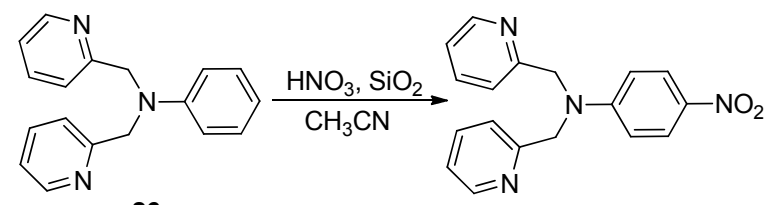

26

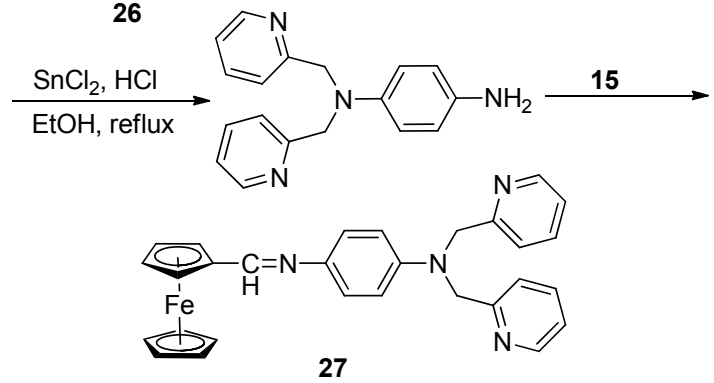

图式 11 二茂铁基受体 27 的合成

Scheme 11 Synthesis of ferrocenyl receptor 27

2018 年, 李鹏起 ${ }^{[66]}$ 以 4-溴-1,8-菜酐(28)为原料, 经 亚胺化后与水合肼反应得到萘酰亚胺，再与二茂铁衍生 物反应合成了新型受体 29 32 (Scheme 12), 其在甲醇 溶液中可以选择性识别 $\mathrm{Ag}^{+}$和 $\mathrm{Cu}^{2+}$. 当加入 $\mathrm{Ag}^{+}$和 $\mathrm{Cu}^{2+}$ 后，化合物 29 和 30 的紫外吸收光谱中 $425 \mathrm{~nm}$ 处的 吸收峰的峰宽逐渐变大, 这是因为化合物与金属离子络 合后改变了二茂铁对萗环的供电能力. 而化合物 31 和 32 没有酰胺结构, 所以无法识别 $\mathrm{Ag}^{+}$.

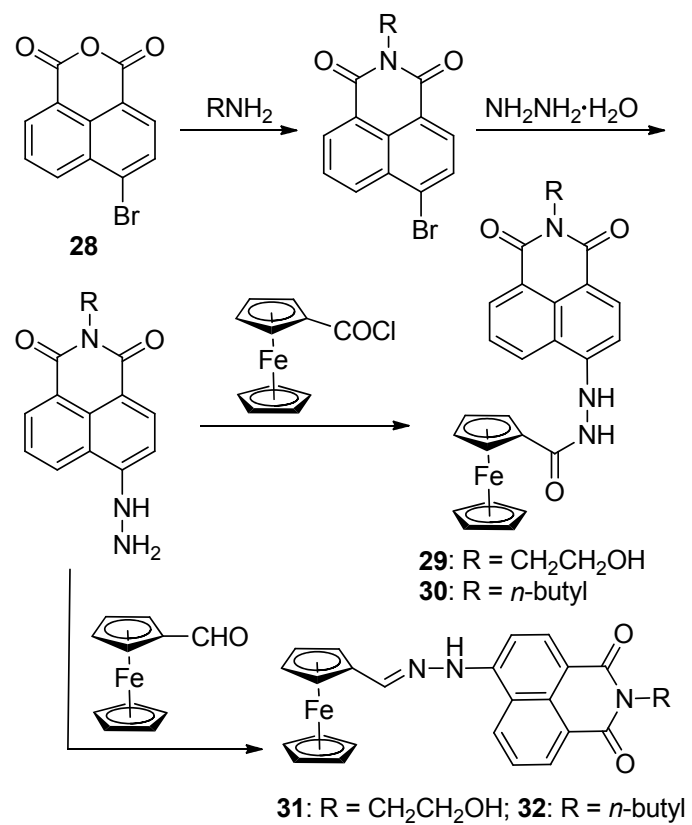

图式 12 二茂铁基受体 29 32 的合成

Scheme 12 Synthesis of ferrocenyl receptors $29 \sim 32$

2019 年，董均阳 ${ }^{[67]}$ 以乙酰基二茂铁对甲苯磺酰腙 
(33)为原料合成了一种基于二茂铁-䒬酰亚胺类衍生物 34 (Scheme 13), 荧光滴定光谱表明, 化合物 34 是一个 $\mathrm{Cu}^{2+}$ 苂光增强型和 $\mathrm{Hg}^{2+}$ 苂光猝灭型的双功能苂光探针. 当 $\mathrm{Cu}^{2+}$ 和 $\mathrm{Hg}^{2+}$ 加入到化合物的水溶液中后, 溶液颜色 由黄色变为无色, 可以实现裸眼识别. 通过机理研究发 现, 化合物 34 与 $\mathrm{Hg}^{2+}$ 的识别位点是化合物中的氮原子 和硫原子. 此外, 在对活体细胞的研究中, 34 可以用来 检测活细胞中 $\mathrm{Cu}^{2+}$ 和 $\mathrm{Hg}^{2+}$.

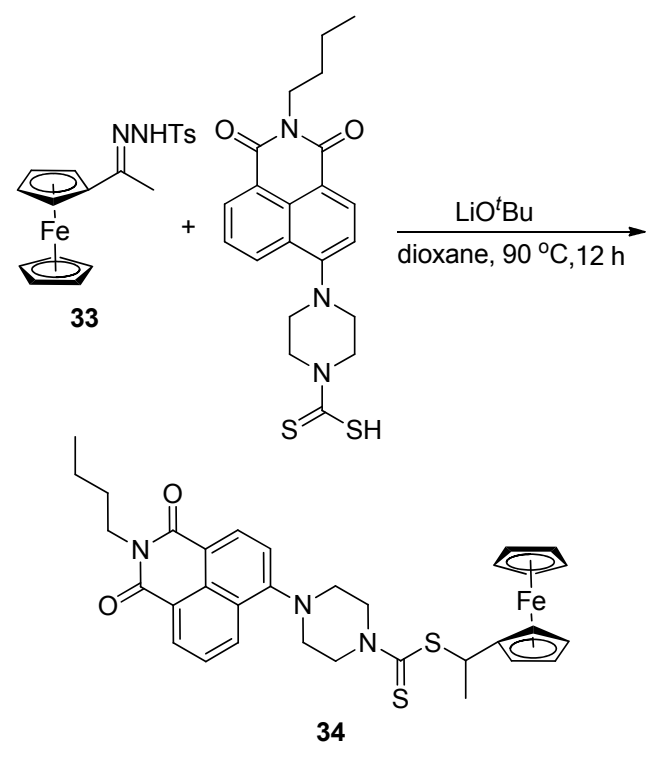

图式 13 二茂铁基受体 34 的合成

Scheme 13 Synthesis of ferrocenyl receptor 34

\section{3 二茂铁共轭类受体}

含共轭体系的二茂铁受体由于存在丰富的 $\pi$ 电子而 引起化学家们极大的兴趣 ${ }^{[68-69]}$. 经研究发现, 当二茂铁 配体与罗丹明、萗或葱等荧光基团相连时, 可使分子在 离子识别过程中不仅发生电化学信号响应, 还使其荧光 及紫外光谱产生一定程度变化 ${ }^{[70-72]}$. 这种多信号响应的 二茂铁化学传感器, 可以极大地提高离子检测的准确 性.

2012 年, 赵小芳等 ${ }^{[73]}$ 以乙炔二茂铁为原料, 与对碘 苯胺经 Sonogashira 偶联反应得到的化合物 35, 再与 9葱甲醛缩合合成了一种二茂铁-葱二元化合物 36 (Scheme 14). 在乙腈溶液中, 当滴加各种金属离子后发 现, 36 对 $\mathrm{Hg}^{2+}, \mathrm{Cu}^{2+}$ 及 $\mathrm{Cr}^{3+}$ 显示出多种信号响应, 紫外 图谱显示化合物 36 位于 $407 \mathrm{~nm}$ 处的吸收峰发生约 100 $\mathrm{nm}$ 红移, 且溶液颜色由肉眼可辨的淡黄色变为玫红色. 电化学实验表明化合物的氧化还原电位向阳极移动. 同 时, 苂光光谱表明 36 对 $\mathrm{Cr}^{3+}$ 显示荧光增强效应. 此外, 核磁谱图结果表明, 向化合物 36 中滴加 $\mathrm{Cr}^{3+}$ 时, $\mathrm{CH}=\mathrm{N}$ 中的质子化学位移向低场移动, 表明 $\mathrm{Cr}^{3+}$ 与化合物 $\mathbf{3 6}$
结构中的 $\mathrm{N}$ 原子发生了配位.
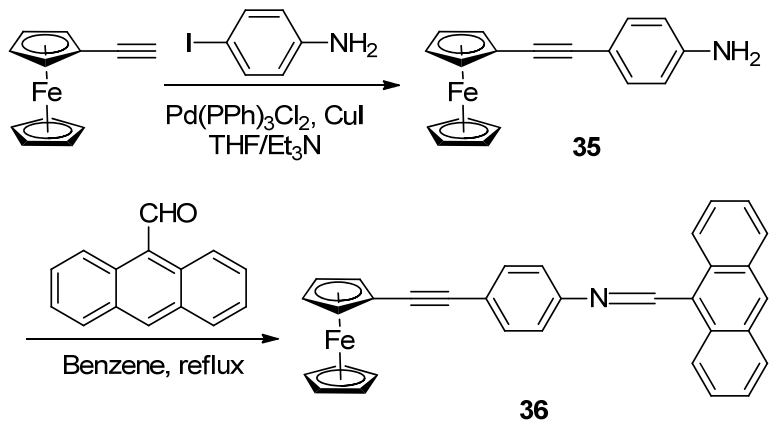

图式 14 二茂铁基受体 36 的合成

Scheme 14 Synthesis of ferrocenyl receptor 36

2014 年, 王健春等 ${ }^{[74]}$ 以二茂铁为原料, 经乙酰化和 Vilsmeier-Haack 反应得到的 1-氯-1-二茂铁基丙烯醛，再 与二酮经环合反应合成了一种二茂铁共轭类化合物 37 (Scheme 15). 在乙醇溶液中, 化合物 37 可以选择性识 别 $\mathrm{Sn}^{4+}, \mathrm{Cr}^{3+}, \mathrm{Fe}^{3+}$ 和 $\mathrm{Cu}^{2+}$, 这四种离子的加入会引起紫 外光谱发生显著改变, 同时溶液颜色由淡黄色逐渐转变 为红色, 可以实现裸眼识别.
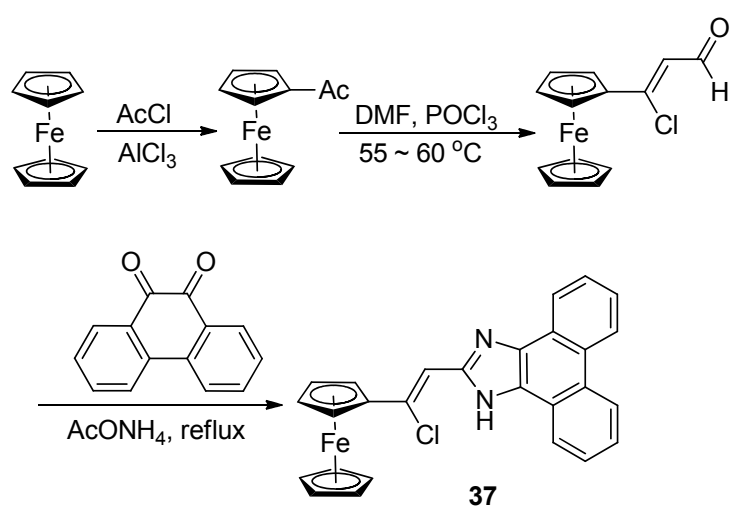

图式 15 二茂铁基受体 37 的合成

Scheme 15 Synthesis of ferrocenyl receptor 37

2015 年, Arivazhagan 等 ${ }^{[75]}$ 以单(叠氮甲基)二茂铁 (38) 和 2-(丙-2-炔氧基)苯甲醛为原料合成了两种三坐二 茂铁-罗丹明共轭化合物 39 和 40 (Scheme 16), 通过光 学法发现其可以在水介质中选择性识别 $\mathrm{Hg}^{2+}$. 紫外谱 图显示, 加入 $\mathrm{Hg}^{2+}$ 后, 化合物 39 和 $\mathbf{4 0}$ 分别在 528 和 556 $\mathrm{nm}$ 处出现新的吸收带, 同时溶液颜色从无色分别变为 红色和粉红色, 可以实现裸眼识别. Fang 等 ${ }^{[76]}$ 也合成了 一种二茂铁-罗丹明化合物 41 . 当化合物 41 与水溶液中 的 $\mathrm{Cu}^{2+}$ 相互作用时, 化合物 $\mathbf{4 1}$ 中的螺环开环, 在 530 $\mathrm{nm}$ 处出现一个新的紫外吸收峰, 荧光效应也逐渐增强, 同时溶液颜色从暗黄色变为亮黄色. 此外, 荧光滴定显 示化合物对 $\mathrm{Cu}^{2+}$ 的检出限为 $6.96 \times 10^{-7} \mathrm{~mol} / \mathrm{L}$. 


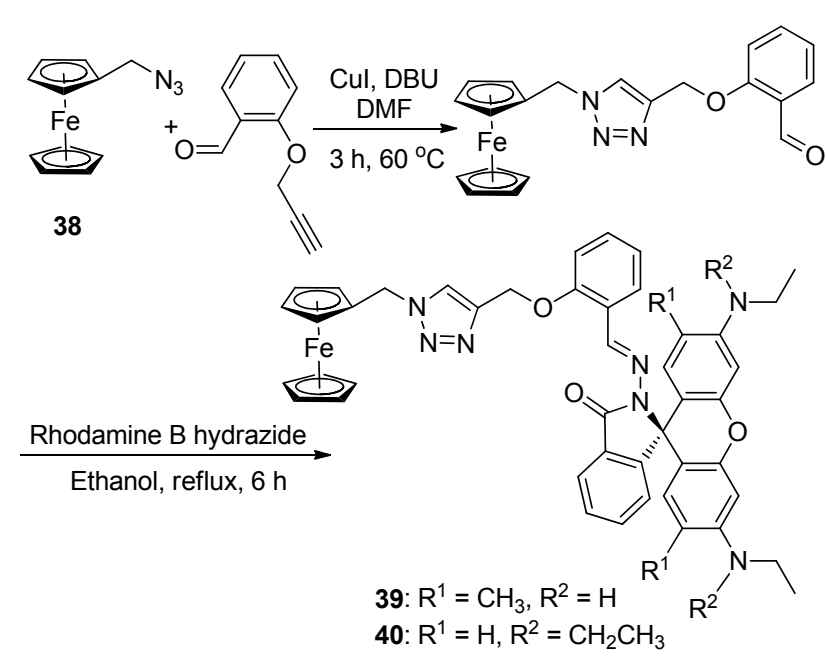

图式 16 二茂铁基受体 39 和 40 的合成

Scheme 16 Synthesis of ferrocenyl receptors 39 and $\mathbf{4 0}$

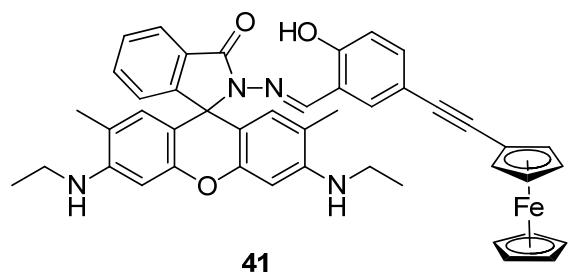

2016年, Teng 等 ${ }^{[77]}$ 通过含乙酰基的二茂铁对甲苯磺 酰腙(33)与 2-颈基苯并咪唑反应合成了一种二茂铁基硫 醚配体 42 (Scheme 17), 其可以有效地识别乙腈溶液中 的 $\mathrm{Hg}^{2+}$. 加入 $\mathrm{Hg}^{2+}$ 后, 紫外谱图发生显著变化, 且化合 物 42 与 $\mathrm{Hg}^{2+}$ 形成 $1: 1$ 型配合物. Liu 等 ${ }^{[78]}$ 以 33 与葱 $-5-$ 甲醛为原料合成了二茂铁基叠氮化合物 $\mathbf{4 3}$ (Scheme 17), 其可以识别水溶液中的 $\mathrm{Hg}^{2+}$ 和 $\mathrm{Cu}^{2+}$. 加入 $\mathrm{Hg}^{2+}$ 或 $\mathrm{Cu}^{2+}$ 后, 体系颜色由黄色变为无色. 荧光谱图显示, 随着金 属离子的加入, 化合物的苂光强度逐渐增加.

2017 年, $\mathrm{Hu}$ 等 ${ }^{[79]}$ 将化合物 33 与 2-芸乙二醇反应合 成了二茂铁基硫醚化合物 44,44 再经氧化生成了二茂铁 基砜 45 (Scheme 17). 在乙腈溶液中, 硫醚 44 可以通过 紫外可见光谱和电化学等检测方法选择性识别 $\mathrm{Hg}^{2+}$. 当 硫醚被氧化为 45 时, 对 $\mathrm{Cu}^{2+}$ 具有更高的选择性识别能 力. 当与 $\mathrm{Cu}^{2+}$ 相互作用后, 体系颜色由无色变为绿色, 可实现裸眼识别.

2018 年, Zhou 等 ${ }^{[80]}$ 报道了一种基于二茂铁和手性 1,1'-联蒜酚的新型化合物 46 (Scheme 18), 向体系中加 入 $\mathrm{Al}^{3+}$ 后, 其氧化还原电位向更正的方向移动, 苂光强 度提高约 200 倍. 在核磁共振和质谱的基础上, 推出化 合物 46 与 $\mathrm{Al}^{3+}$ 形成 $1: 2$ 配合物.

2019 年, 伶例 ${ }^{[81]}$ 以乙酰基二茂铁衍生的腙和二苯 基膦氧为底物合成了一系列含二茂铁基磷酰腙类共轭 化合物(Scheme 19), 其中化合物 $\mathbf{4 7}$ 和 $\mathbf{4 8}$ 的紫外谱图和

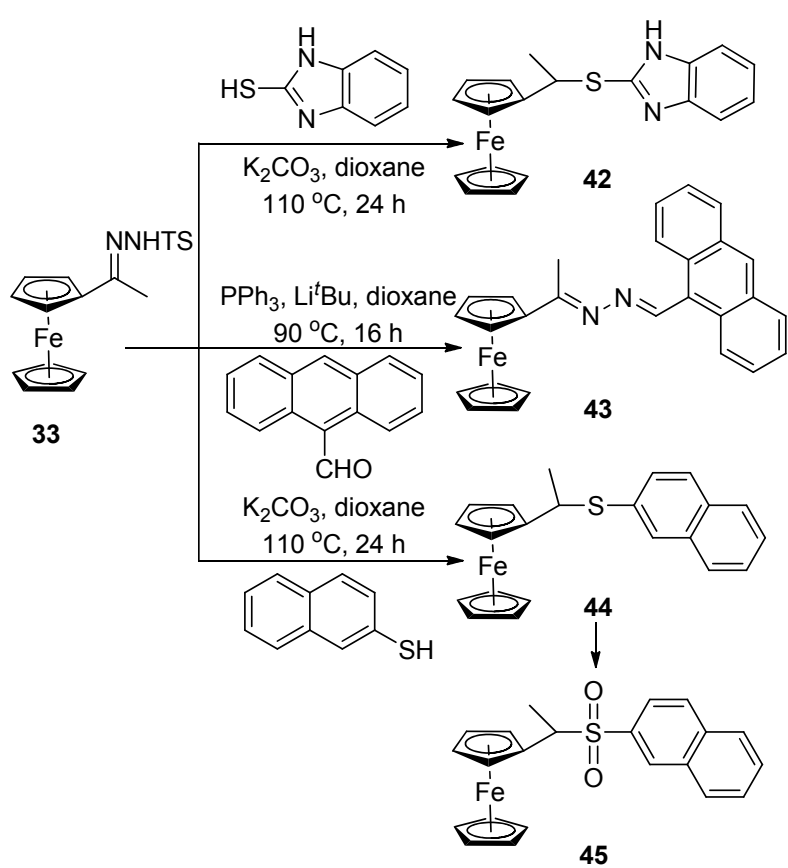

图式 17 二茂铁基受体 42 45 的合成

Scheme 17 Synthesis of ferrocenyl receptors $\mathbf{4 2} \sim \mathbf{4 5}$

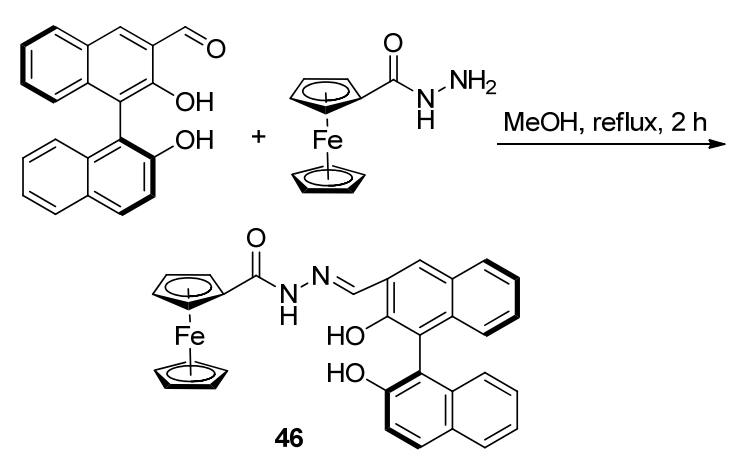

图式 18 二茂铁基受体 46 的合成

Scheme 18 Synthesis of ferrocenyl receptor 46

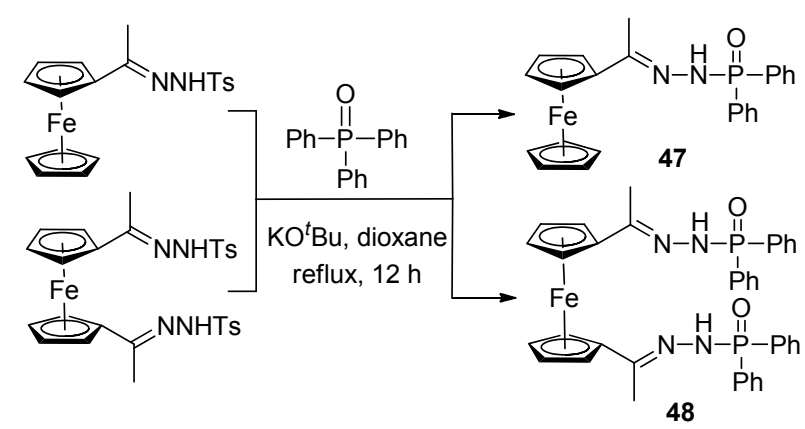

图式 19 二茂铁基受体 47 和 48 的合成 Scheme 19 Synthesis of ferrocenyl receptors 47 and 48 循环伏安曲线均显示出对 $\mathrm{Hg}^{2+}$ 和 $\mathrm{Cu}^{2+}$ 的高度选择性识 别. 当加入 $\mathrm{Hg}^{2+}$ 或 $\mathrm{Cu}^{2+}$ 时, 溶液颜色从浅黄色分别变为 红色和黄绿色, 可以实现裸眼识别.

些婧欣 ${ }^{[82}$ 报道了一种可以通过电化学和紫外可见 
光谱等检测的识别 $\mathrm{Cu}^{2+}$ 的二茂铁环亚砜类化合物 49 (Scheme 20), 其与 $\mathrm{Cu}^{2+}$ 的络合比为 $1: 1$, 且可达到裸 眼识别. 通过计算得出, 在乙腈溶液中, 其对 $\mathrm{Cu}^{2+}$ 的最 低检测限分别为 $9.6 \times 10^{-7} \mathrm{~mol} / \mathrm{L}$, 络合常数为 $7.188 \times$ $10^{4}$.
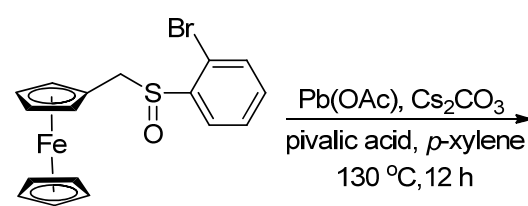
$130^{\circ} \mathrm{C}, 12 \mathrm{~h}$

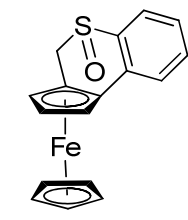

49

图式 20 二茂铁基受体 49 的合成

Scheme 20 Synthesis of ferrocenyl receptor 49

\section{4 二茂铁杂环类受体}

目前, 含氮、氧、硫等杂原子的环状化合物在金属 离子识别中应用广泛, 主要集中在三唑、咪唑、吡啶、 噻唑、吡唑啉等芳杂环受体分子 ${ }^{[83-88]}$. 芳杂环化合物中 含有的 $\mathrm{N} 、 \mathrm{~S}$ 和 $\mathrm{O}$ 等原子可以与金属离子进行稳定的配 位，同时，芳杂环本身具有良好的荧光性，可同时作为 受体分子的结合基团和信号响应基团. 在过去十几年 间, 二茂铁杂环类阳离子受体在离子识别中占有越来越 重要的位置 ${ }^{[89-90]}$.

2011 年, Shi 等 ${ }^{[91]}$ 以二茂铁甲酰氯和 8-羟基喹啉为 原料设计合成了 8-着基喹啉二茂铁受体 50 (Scheme 21), 其可以通过多通道在水溶液中高选择性识别 $\mathrm{Hg}^{2+}$. 化 合物 50 与 $\mathrm{Hg}^{2+}$ 络合后, 紫外图谱显示其特征吸收峰红 移, 苂光强度在 $303 \mathrm{~nm}$ 处猝灭.

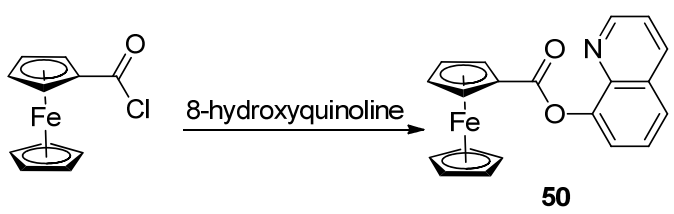

图式 21 二茂铁基受体 $\mathbf{5 0}$ 的合成

Scheme 21 Synthesis of ferrocenyl receptor 50

同年, Molina 等 ${ }^{[92-93]}$ 用二茂铁甲醛(15)和芘-4,5-二 酮缩合, 制备了一种二茂铁咪唑类化合物 51 (Scheme 22), 其可以选择性识别乙腈溶液中的 $\mathrm{Cu}^{2+}, \mathrm{Hg}^{2+}, \mathrm{Zn}^{2+}$ 和 $\mathrm{Pb}^{2+}$ 等金属离子. 紫外图谱显示, 向体系中加入 $\mathrm{Hg}^{2+}$ 或 $\mathrm{Pb}^{2+}$ 后, 化合物均出现新的吸收峰, 同时体系颜色发 生明显变化. 苂光滴定实验表明, 在 $\mathrm{Hg}^{2+}$ 存在下受体 $\mathbf{5 1}$ 表现出明显的红移和强度增强. 2013 年, 该课题组 ${ }^{[94]}$ 还 以 15 为原料, 经过一系列反应合成了 2,7 -二取代苯并咪 唑衍生物 52 (Scheme 22), 其可以在乙腈和甲醇溶液中 通过多种通道识别 $\mathrm{Hg}^{2+}, \mathrm{Zn}^{2+}$ 和 $\mathrm{Pb}^{2+}$. 在加入 $\mathrm{Pb}^{2+}$ 后, 化合物 52 的紫外吸收光谱中出现一个新的低能带, 从
而导致体系颜色由无色变为淡黄色.

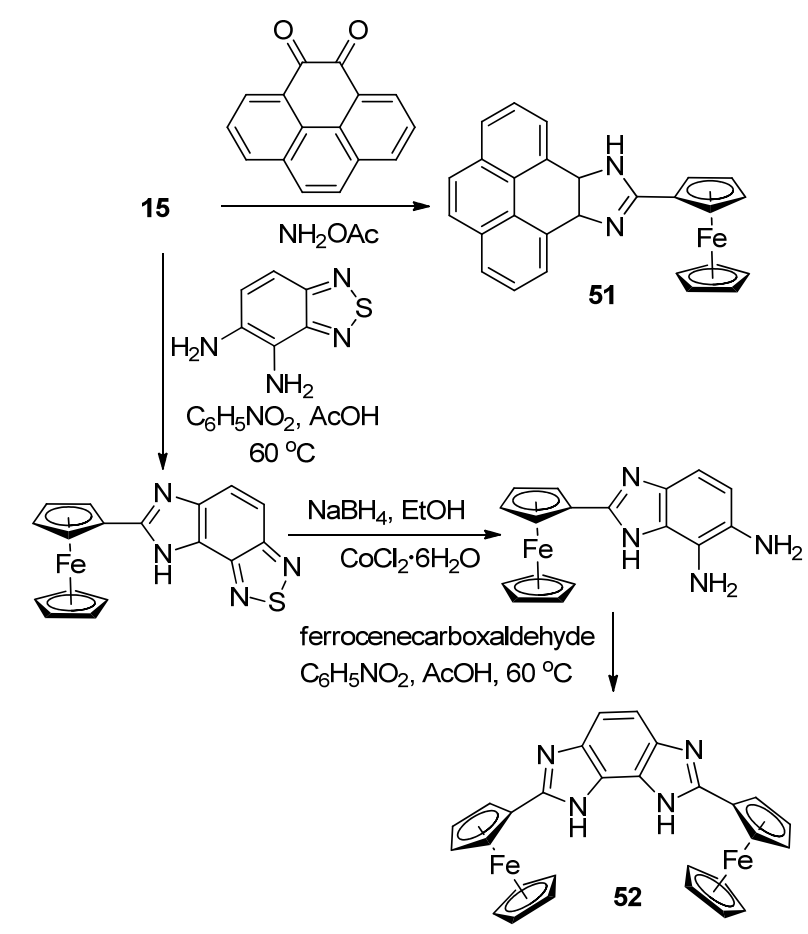

图式 22 二茂铁基受体 51 和 52 的合成

Scheme 22 Synthesis of ferrocenyl receptors $\mathbf{5 1}$ and $\mathbf{5 2}$

2012 年, Ghosh 等 ${ }^{[95]}$ 用化合物 $\mathbf{5 3}$ 和 2-叠氮乙酸苠酯 反应得到了一种三唑类二茂铁苯乙酸衍生物 54 (Scheme 23), 通过电化学、光学和比色法发现其能选择 性识别 $\mathrm{Hg}^{2+} 、 \mathrm{Ni}^{2+}$ 和 $\mathrm{Cu}^{2+}$, 并显示出较大的电化学信号 变化. 同时, 54 可以在 $\mathrm{Cu}^{2+}$ 和 $\mathrm{Ni}^{2+}$ 等竞争性金属离子的 存在下选择性识别水中 $\mathrm{Hg}^{2+}$, 还可用于在除 $\mathrm{Hg}^{2+}$ 外的 其它竞争离子的存在下识别 $\mathrm{Ni}^{2+}$.

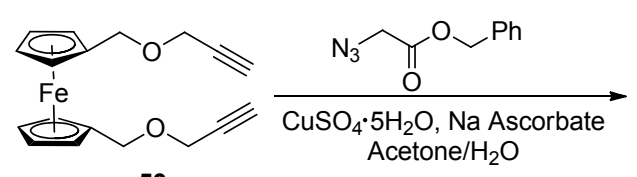

53

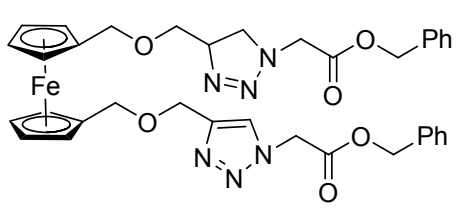

54

图式 23 二茂铁基受体 54 的合成

Scheme 23 Synthesis of ferrocenyl receptor 54

2012 年, Sathyaraj 等 ${ }^{[96]}$ 以二茂铁甲醛(15)为原料, 与 2,3-丁二酮反应得到( $1 E, 5 E$ )-1,6-二茂铁基已基-1,5-二 烯-3,4-二酮，再与水杨醛反应得到二茂铁咪唑受体 55 (Scheme 24), 其可以选择性识别部分金属阳离子. 电化 学实验结果表明, 在乙腈溶液中, 随着 $\mathrm{Fe}^{2+}, \mathrm{Cu}^{2+}, \mathrm{Co}^{2+}$ 
和 $\mathrm{Ni}^{2+}$ 等阳离子的逐步加入, 化合物 $\mathbf{5 5}$ 的氧化还原电 位正移. 紫外光谱显示, 化合物 55 分别与 $\mathrm{Fe}^{2+}, \mathrm{Cd}^{2+}$ 和 $\mathrm{Co}^{2+}$ 等离子络合后, 其 $363 \mathrm{~nm}$ 处的吸收峰发生明显的 红移.

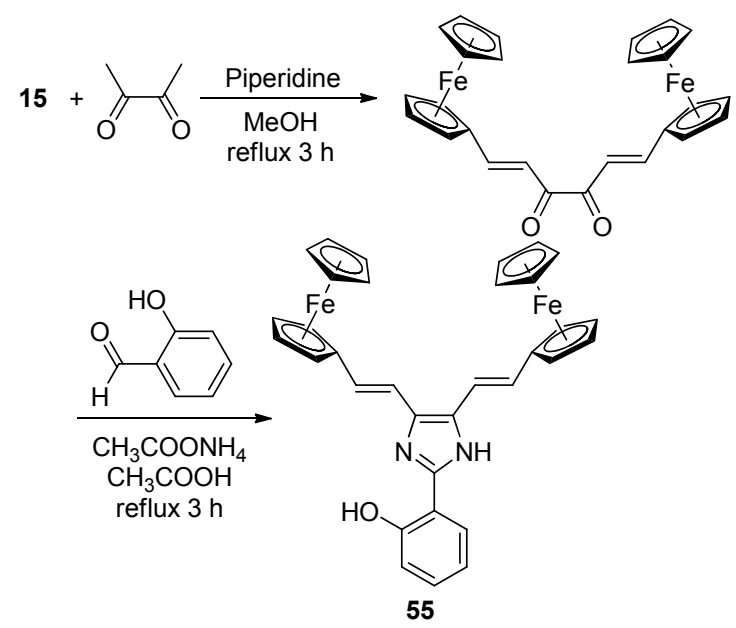

图式 24 二茂铁基受体 55 的合成

Scheme 24 Synthesis of ferrocenyl receptor 55

2013 年, Romero 等 ${ }^{[97]}$ 用叠氮二茂铁(56)和 2-炔基4(3H)-喹唑林酮反应, 制备了一种可以选择性识别乙腈 溶液中的 $\mathrm{Hg}^{2+} 、 \mathrm{Ni}^{2+}$ 和 $\mathrm{Pb}^{2+}$ 等离子的二茂铁三唑衍生物 57 (Scheme 25). 循环伏安图显示, 向体系中逐步加入 $\mathrm{Hg}^{2+}$ 导致化合物氧化还原峰向正向移动.

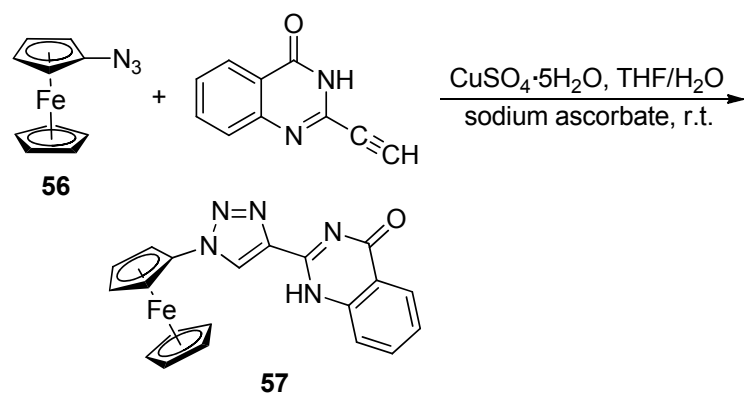

图式 25 二茂铁基受体 57 的合成

Scheme 25 Synthesis of ferrocenyl receptor $\mathbf{5 7}$

2013, Kumar 等 ${ }^{[98]}$ 用乙酰基二茂铁(58)与芳香醛反 应得到相应的查尔酮后, 再与 2-肼吡啶回流合成了二茂 铁基吡唑啉类受体 59 (Scheme 26), 通过电化学法和光 学法检测到其可以选择性识别二氯甲烷中的 $\mathrm{Cu}^{2+}, \mathrm{Co}^{2+}$ 和 $\mathrm{Zn}^{2+}$. 此外, 当化合物与阳离子结合后, 吸收光谱红 移, 同时溶液由黄色变为红色. 2015 年, 该课题组 ${ }^{[99]}$ 在 此基础上又合成了一种二茂铁基吡唑啉类受体 60 (Scheme 26). 该受体可以多通道高选择性识别乙腈溶 液中的 $\mathrm{Cu}^{2+}$ 和 $\mathrm{Hg}^{2+}$, 通过比色法可观察到随着 $\mathrm{Cu}^{2+}$ 的 加入体系溶液颜色由黄色变为红色. 由核磁滴定观察
到，随着 $\mathrm{Cu}^{2+}$ 或 $\mathrm{Hg}^{2+}$ 的加入，化合物二茂铁部分未取代 的质子、吡唑啉环上的质子以及 2-苯并噻唑环上质子的 化学位移均向低场移动, 表明 $\mathrm{Cu}^{2+}$ 和 $\mathrm{Hg}^{2+}$ 分别与 2-苯 并噻唑和吡唑啉环上的氮原子相互作用.

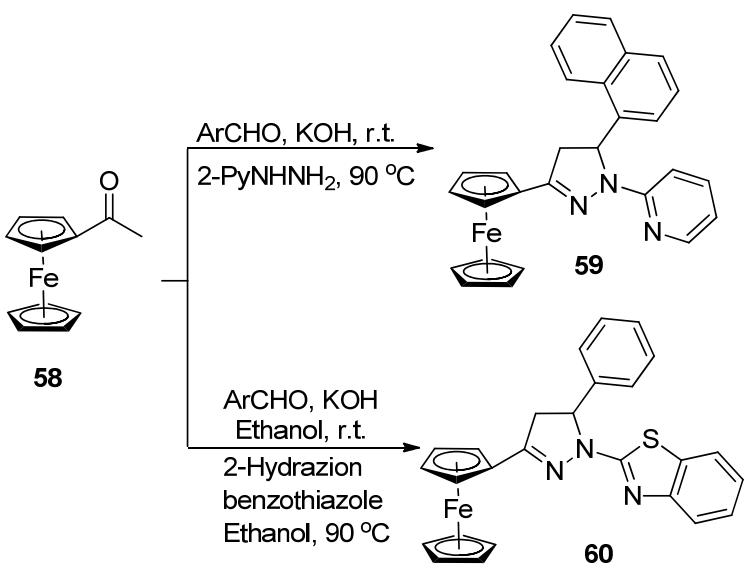

图式 26 二茂铁基受体 59 和 60 的合成

Scheme 26 Synthesis of ferrocenyl receptors 69 and 60

2013 年, Thakur 等 ${ }^{[100]}$ 以双取代二茂铁叠氮化合物 61 为原料，经环加成反应合成了二茂铁基三唑类化合 物 62 (Scheme 27), 其能够在 $\mathrm{Hg}^{2+}$ 和 $\mathrm{Cd}^{2+}$ 等竞争性金属 离子的存在下于水环境中高选择性识别 $\mathrm{Pb}^{2+}$, 同时溶液 颜色由黄色变为蓝绿色, 可以达到裸眼识别. 此外, 化 合物 62 能够检测出河水样本中的 $\mathrm{Pb}^{2+}$.
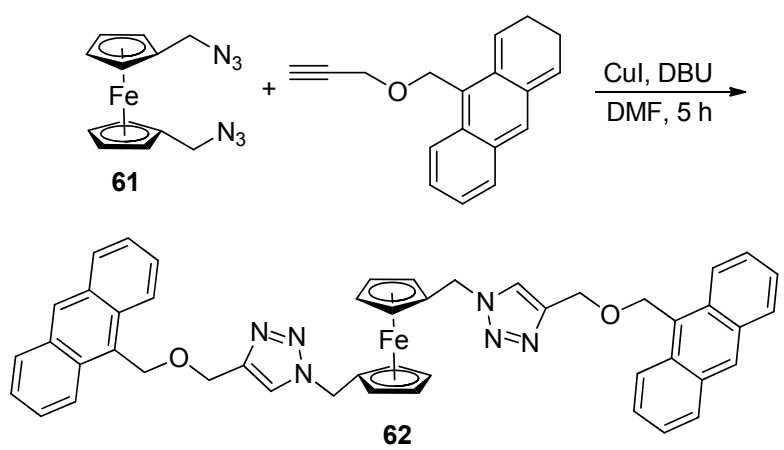

图式 27 二茂铁基受体 62 的合成

Scheme 27 Synthesis of ferrocenyl receptor 62

2015 年, 王智成等 ${ }^{[101]}$ 以 61 为原料通过 Click 反应 合成了一种含䒺酚与二茂铁基的环三唑化合物 63 (Scheme 28), 其对乙腈溶液中的 $\mathrm{Zn}^{2+}$ 有着很好的荧光 及电化学信号响应. 由核磁氢谱滴定观察到, 随着 $\mathrm{Zn}^{2+}$ 的滴加，化合物中三唑环上的质子及与 $\mathrm{O}$ 相连的亚甲基 上的质子化学位移向低场移动, 表明化合物三唑环中两 个 $\mathrm{N}$ 原子和醚键上的 $\mathrm{O}$ 原子参与了配位. 


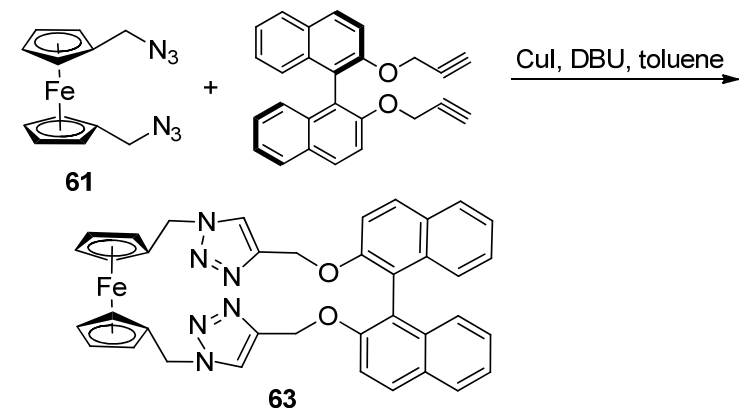

图式 28 二茂铁基受体 63 的合成

Scheme 28 Synthesis of ferrocenyl receptor 63

2017, Bhatta 等 ${ }^{[102]}$ 采用同样的方法合成了一种二茂 铁三唑类受体 64 (Scheme 29), 其能够选择性识别且区 分水介质中的 $\mathrm{Fe}^{2+}$ 和 $\mathrm{Fe}^{3+}$. 经研究发现 $\mathrm{Fe}^{2+}$ 的存在对 $\mathrm{Fe}^{3+}$ 的检测没有产生明显影响, 而较小量的 $\mathrm{Fe}^{3+}$ 会阻碍 了 $\mathrm{Fe}^{2+}$ 的检测, 该类受体可选择性地区分 $\mathrm{Fe}^{3+}$ 和 $\mathrm{Fe}^{2+}$.<smiles>C#CCOc1ccc2ccccc2c1CO</smiles><smiles></smiles>

图式 29 二茂铁基受体 64 的合成

Scheme 29 Synthesis of ferrocenyl receptor 64

2017 年, 邬孝芳等 ${ }^{[103]}$ 以氯乙酰基二茂铁(65)和 2統基苯并咪唑为原料设计合成了二茂铁噻唑类衍生物 66 (Scheme 30), 其可选择性识别 $\mathrm{Fe}^{3+}$. 通过机理研究表 明, 化合物在四氢呋喃中存在烯醇互变异构现象, 且 $\mathrm{Fe}^{3+}$ 的显色反应是一个三元体系, 即配体、四氢呋喃和 $\mathrm{Fe}^{3+}$.
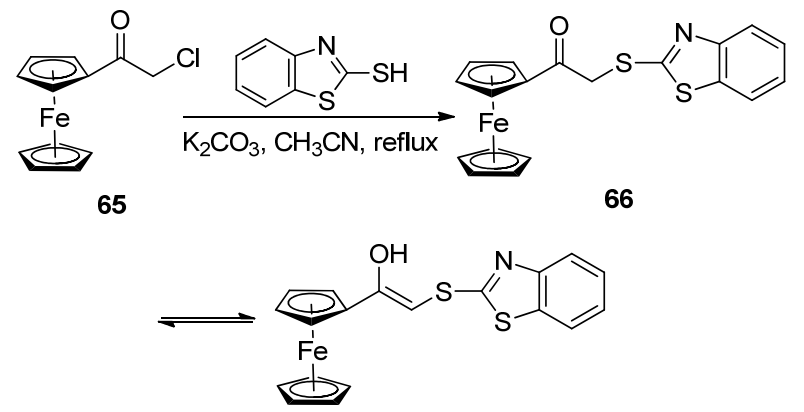

图式 30 二茂铁基受体 66 的合成 Scheme 30 Synthesis of ferrocenyl receptor $\mathbf{6 6}$
2017 年，任亚平等 ${ }^{[104]}$ 以对二茂铁苯甲酸和 2-氨基5-芳基-1,3,4-噻二唑化合物为原料，合成了二茂铁苯甲 酰塞二唑受体 67 (Scheme 31), 其对 $\mathrm{Pb}^{2+}$ 和 $\mathrm{Zn}^{2+}$ 都有一 定的电化学响应. 电化学研究表明, 在 DMF 溶液中随 着 $\mathrm{Pb}^{2+}$ 和 $\mathrm{Zn}^{2+}$ 的加入, 化合物 67 的氧化还原峰均发生 一定程度的移动.

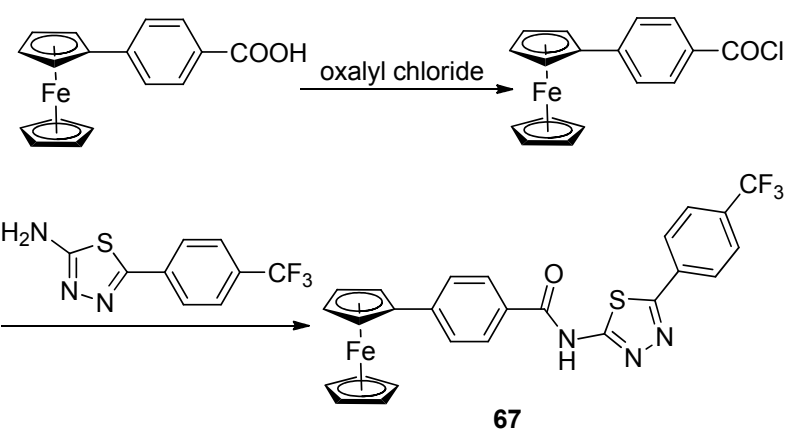

图式 31 二茂铁基受体 67 的合成

Scheme 31 Synthesis of ferrocenyl receptor 67

2018 年, 候静娜等 ${ }^{[105]}$ 用二茂铁甲醛(15)分别与 2,2'-二吡啶基乙二酮、2,2'-二噻吩基乙二酮反应合成了 两种二茂铁咪唑类化合物 68 和 69 (Scheme 32), 其可通 过多种通道识别乙腈溶液中的 $\mathrm{Al}^{3+}$ 和 $\mathrm{Cr}^{3+}$. 此外, 化合 物 68 对 $\mathrm{Al}^{3+}$ 的荧光响应明显高于 $\mathrm{Cr}^{3+}$, 作者推测是因 为引入了配位能力较强的 $\mathrm{N}$ 原子而增强了选择性.

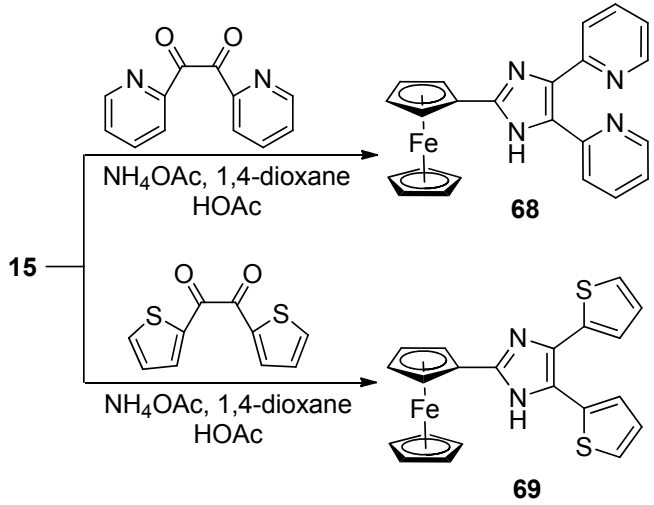

图式 32 二茂铁基受体 68 和 69 的合成

Scheme 32 Synthesis of ferrocenyl receptors 68,69

2018 年, 孙琦 ${ }^{[106]}$ 以二茂铁对甲苯磺酰腙 $(33)$ 与咔 唑衍生物反应, 制备了两种可以选择性识别 $\mathrm{Cu}^{2+}$ 和 $\mathrm{Hg}^{2+}$ 的二茂铁咔唑类化合物 70 和 71 (Scheme 33). 在乙 腈溶液中, 随着 $\mathrm{Cu}^{2+}$ 或 $\mathrm{Hg}^{2+}$ 的加入, 体系颜色由无色变 为黄色或红色，并且在苂光灯照射下具有蓝色苂光. 化 合物 71 可以选择识别 $\mathrm{Cu}^{2+}$ 和 $\mathrm{Hg}^{2+}$ 而不受其他金属阳离 子的干扰，当加入这两种离子后苂光分别增强了 40 倍 和 38 倍.

2019 年, 贾慧劼等 ${ }^{[107]}$ 以二茂铁甲醛(15)为起始原 


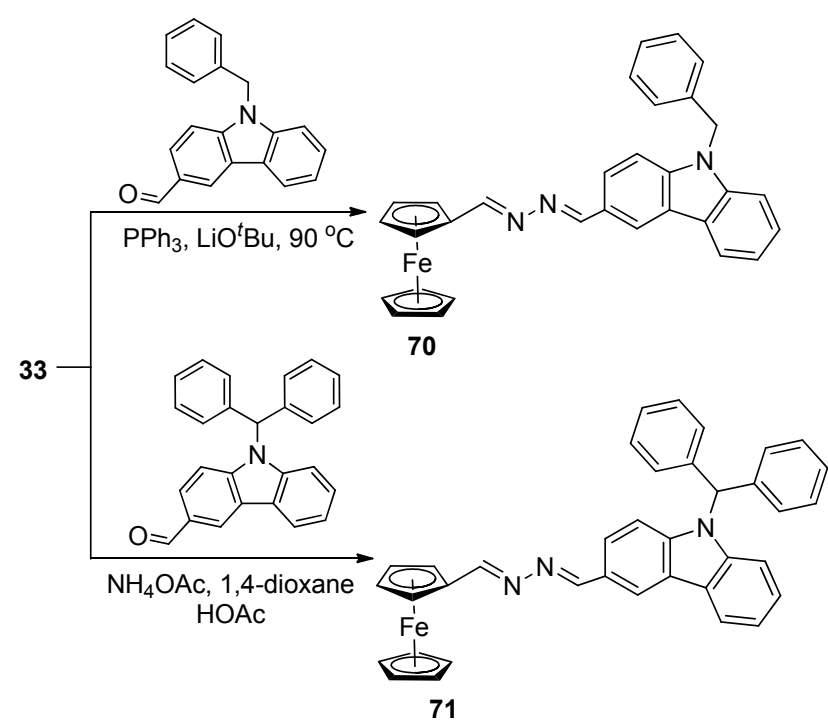

图式 33 二茂铁基受体 70 和 71 的合成

Scheme 33 Synthesis of ferrocenyl receptors 70 and 71

料, 经环合、乙酰化反应合成了一种乙酰基二茂铁苯并 噻唑化合物 72 (Scheme 34), 其可以选择性识别乙腈溶 液中 $\mathrm{Al}^{3+}, \mathrm{Cr}^{3+}$ 和 $\mathrm{Fe}^{3+}$. 荧光分析显示, 对 $\mathrm{Al}^{3+}, \mathrm{Cr}^{3+}$ 和 $\mathrm{Fe}^{3+}$ 的最低检测限分别是 $7.456 \times 10^{-6}, 3.72 \times 10^{-6}$, $1.35 \times 10^{-5} \mathrm{~mol} / \mathrm{L}$.

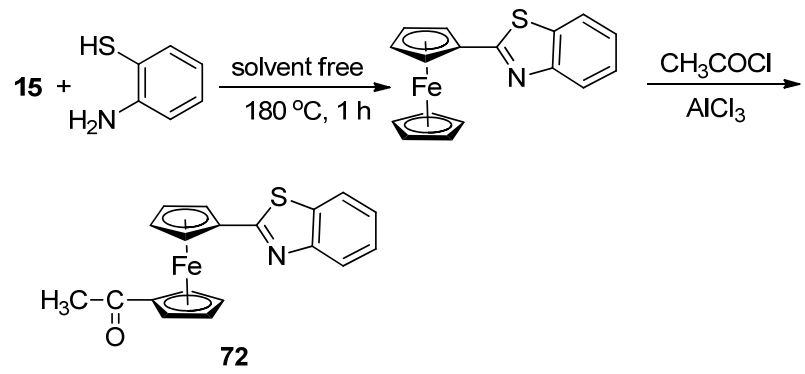

图式 34 二茂铁基受体 72 的合成

Scheme 34 Synthesis of ferrocenyl receptor $\mathbf{7 2}$

2020 年, $\mathrm{Xu}$ 等 ${ }^{[108]}$ 用叠氮二茂铁 $(\mathbf{5 6})$ 与喹啉衍生物 反应合成了三唑键合的二茂铁基喹啉受体 73 (Scheme $35)$, 在乙腈/水 $(V: V=1: 4)$ 混合溶剂中其能够选择性 识别 $\mathrm{Cu}^{2+}$. 同时颜色由黄色变为绿色, 可以用于裸眼识 别水溶液中的 $\mathrm{Cu}^{2+}$, 且不受其他竞争性阳离子的干扰.

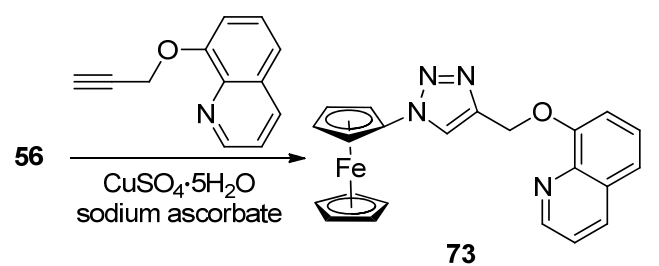

图式 35 二茂铁基受体 73 的合成

Scheme 35 Synthesis of ferrocenyl receptor $\mathbf{7 3}$

\section{5 结束语}

基于二茂铁的金属阳离子识别受体的研究深受科 研人员的青睐. 从所用原料、合成方法、分子结构等方 面进行设计合成了多种二茂铁阳离子识别受体. 通过光 学法、电化学法和苂光检测法对二茂铁衍生物在金属阳 离子选择性传感方面进行了分析，同时也通过比色法发 现部分受体识别金属离子可以实现裸眼观察. 目前，以 二茂铁为骨架的金属阳离子识别受体的研究已取得了 显著的成果. 然而, 如何合理地设计合成具有更高灵敏 度和高选择性的且可用于生物学、医学及环境科学等多 个领域的二茂铁基金属阳离子识别受体，仍然是一个富 有挑战性的课题.

\section{References}

[1] Kealy, T. J.; Pauson, P. L. J. Nature 1951, 168, 1039.

[2] Huang, Y.-J.; Lin, J.-S.; Zhang, W.-K.; Zhang, B.-G.; Sun, Q.-Z. Inorg. Chem. Commun. 2019, 105, 129.

[3] Liu, Y.-T.; Yang, L.-S.; Yin, D.-W.; Dang, Y.; Yang, L.; Zou, Q.; Li, J.; Sun, J.-X. J. Organomet. Chem. 2019, 899, 120903.

[4] Rajalakshmi, A. V.; Palanisaml, N. Spectrochim. Acta, Part A 2020, 228,117812

[5] Dewangan, S.; Barik, T.; Parida, R.; Mawatwal, S.; Dhiman, R.; Giri, S.; Chatterjee, S. J. Organomet. Chem. 2019, 904, 120999.

[6] Wu, K.-L.; Zhang, W.-B.; Zhou, D.; Xu, Y. Chin. J. Org. Chem. 2014, 34, 1201 (in Chinese). (吴孔丽, 张吾斌, 周丹, 徐琰, 有机化学, 2014, 34, 1201.)

[7] Wang, X.-X.; Qi, Y.-X.; Shen, Y.; Yuan, Y.; Zhang, L.; Zhang, C.-Y.; Sun, Y.-H. Sens. Actuators, B 2020, 310, 127756.

[8] Yu, L.-J.; Wu, L.; Wang, L.-J.; Ren, G.-L.; Nui, L.; Guo, H.-M. Chin. J. Anal. Lab. 2020, 39, 97 (in Chinese). (余利娇, 吴亮, 王丽娟, 任桂铃, 牛露, 郭浩模, 分析实验室, 2020, 39, 97.)

[9] Xiao, W.-J.; Cao, H.-Y.; Lin, Y.; Liu, W.-Q.; Wan, P.-N.; Cui, H.-F. Chin. J. Synth. Chem. 2020, (4), 341 (in Chinese).

(肖文杰, 曹海泳, 林艳, 刘文琴, 万屏南, 崔汉峰, 合成化学, 2020, (4), 341.)

[10] Kamal, A.; Kumar, K.; Kumar, V.; Mahajan, R. K. Electrochim. Acta 2014, 145, 307.

[11] Qian, C.; Chuo, L.-P.; Zhao, H.-Y.; Bian, Z.-X. Chin. J. Org. Chem. 2017, 37, 2328 (in Chinese).

(钱超, 绰洛鹏, 赵海英, 边占喜, 有机化学, 2017, 37, 2328.)

[12] Liu, Y.-T.; Sheng, J.; Yin, D.-W.; Xin, H.; Yang, X.-M.; Qiao, Q.-Y.; Yang, Z.-J. J. Organomet. Chem. 2018, 856, 27.

[13] Jia, D.-G.; Zheng, J.-A.; Fan, Y.-R.; Yu, J.-Q.; Wu, X.-L.; Wang, B.-J.; Yang, X.-B.; Huang, Y. J. Organomet. Chem. 2019, 888, 16.

[14] Zhao, H.-Y.; Yin, F.-N.; Yu, L.-Y.; Li, B.-G.; Bian, Z.-X. Chin. J. Org. Chem. 2016, 36, 1118 (in Chinese). (赵海英, 尹凤楠, 于玲岩, 李保国, 边占喜, 有机化学, 2016, 36,1118 .)

[15] Niu, X. H.; Mo, Z. L.; Yang, X.; Shuai, C.; Liu, N. J.; Gou, R. B. Bioelectrochemistry 2019, 128, 74.

[16] Wang, X.-C.; Xiao, L.-F.; Wu, J.-Y.; Li, S.-L.; Tian, Y.-P. J. Anhui Univ. (Nat. Sci.) 2017, 16, 28 (in Chinese).

(汪徐春, 肖陆飞, 吴杰颖, 李胜利, 田玉鹏, 安徽大学学报(自 然科学版), 2017, 16, 28.)

[17] Hong, G. L.; Chen, R. T.; Xu, L. Y.; Xing, L.; Yang, Z. Q.; Zhou, G. B.; Li, L.; Chen, W.; Peng, H. P. Anal. Chim. Acta 2020, 1099, 52.

[18] Minic, A.; Bugarinovic, J. P.; Pejovic, A.; Komatina, D. I.; Bogdanovic, G. A.; Damljanovic, I.; Stevanovic, D. Tetrahedron Lett. 2018, 59, 3499.

[19] Korotaev, V. Y.; Kutyashev, L. B.; Barkov, A. Y.; Rozhkova, Y. S.; 
Plekhanova, I. V.; Shklyaev, Y. V.; Sosnovskikh, V. Y. Tetrahedron Lett. 2019, 60, 150916.

[20] Minic, A.; Walle, T. V.; Hecke, K. V.; Combrinck, J.; Smith, P. J.; Chibale, K.; D'hooghe, M. Eur. J. Med. Chem. 2020, 187, 111963.

[21] Liu, Y.-T.; Xin, H.; Yin, J.-Y.; Yin, D.-W.; Yang, Z.-J.; Li, J. J. Mol. Struct. 2018, 1157, 482.

[22] Tan, J.; Chen, L.; Peng, A.-L.; Xiao, J.; Zhang, E.-J. Chin. J. Mod. Appl. Pharm. 2018, 35, 345 (in Chinese). (谭娟，陈灵，彭安林，肖静，张恩景，中国现代应用药学，2018, 35, 345.)

[23] Ren, T.; Zhao, L.-J.; Zhong, R.-G. Chem. Reagents 2020, 42, 797 (in Chinese). (任婷, 赵丽娇, 钟儒刚, 化学试剂, 2020, 42, 797.)

[24] Feng, L.-F.; Du, J.; Yao, C.-J.; Jiang, Z.-Q.; Li, T.; Zhang, Q.; Guo, X.-N.; Yu, M.; Xia, H.-L.; Shi, L.; Jia, J.-L.; Tong, Y.; Ju, L.; Liu, J.-Q.; Lou, J.-L.; Lemos, B. Environ. Int. 2020, $138,105593$.

[25] Ni, P.-W. M.S. Thesis, Lanzhou Jiaotong Universiy, Lanzhou, 2019 (in Chinese).

(倪朋伟, 硕士论文, 兰州交通大学, 兰州, 2019.)

[26] Huang, Y.-J.; Lin, J.-S.; Zhang, W.-K.; Zhang, B.-G.; Sun, Q.-Z. Inorg. Chem. Commun. 2019, 105, 129.

[27] Liu, T.; Liu, X.; Spring, D. R.; Qian, X.; Cui, J.; Xu, Z. Sci. Rep. 2014, 4, 5418.

[28] Qu, F.-M.; Chen, F.; Hou, X.-Z.; Ma, X.-Y. Chin. J. Appl. Chem. 2013, 30, 1393 (in Chinese) (屈枫锦，陈芳，候秀璋，马晓燕，应用化学, 2013, 30, 1393.)

[29] Wang, C.; Wu, J.; Jiang, K.; Humphrey, M. G.; Zhang, C. Sens. Actuator, $B$ 2017, 238, 1136

[30] Saleem, M.; Yu, H.; Wang, L.; Zain-ul-Abdin.; Khalid, H.; Akram, M.; Abbasi, N. M.; Chen, Y. J. Electroanal. Chem. 2016, 763, 71.

[31] Sokolov, V. I. Chin. J. Org. Chem. 2018, 38, 75 (in Chinese). (Sokolov, V. I. 有机化学, 2018, 38, 75.)

[32] Shi, X.-R. Chin. J. Synth. Chem. 2017, 25, 985 (in Chinese). (石修然, 合成化学, 2017, 25, 985.)

[33] Liu, Y. F.; Hu, J. F.; Teng, Q.; Zhang, H. Sens. Actuators, B 2017, $238,166$.

[34] Dang, Y. M.S. Thesis, Shaanxi University of Science \& Technology, Xi'an, 2020 (in Chinese). (党阳，硕士论文，陕西科技大学，西安, 2020.)

[35] Pedersen, C. J. J. Am. Chem. Soc. 1967, 89, 2495.

[36] Ahmed, A.; Hashmi, M. A.; Ayub, K. J. Mol. Liq. 2020, 302, 112577.

[37] Korchowiec, B.; Trojan, S.; Joly, J.-P.; Korchowiec, J.; Beley, M.; Rogalska, E. Thin Solid Films 2019, 683, 49.

[38] Oliveira, E. Santos, H. M. Dyes Pigm. 2016, 135, 3.

[39] Li, J.; Yim, D.; Jang, W.-D.; Yoon, J.-Y. Chem. Soc. Rev. 2017, 46, 2437.

[40] Tian, X.; Yang, F.-Q.; Yuan, W.; Zhao, L.; Yao, L.; Zhen, X.-L.; Han, J.-R.; Liu, S.-X. Chem. J. Chin. Univ. 2020, 41, 490 (in Chinese)

(田霞, 杨福群, 袁伟, 赵雷, 姚雷, 甄小丽, 韩建荣, 刘守信, 高等学校化学学报, 2020, 41, 490.)

[41] Agurto, N.; Maldonado, T.; Godoy, F.; Gomez, A.; Silva, C. P.; Pavez, J.; Ferraudi, G.; Oliver, A.; Lappin, A. G. J. Organomet. Chem. 2017, 827, 32.

[42] Xiong, J.; Tan, M.-K.; Lu, S.-F.; Li, M.; Yang, S.-B. Chin. J. Inorg. Chem. 2019, 35, 1805 (in Chinese).

(熊俊, 谭茂坤, 吕少仿, 李明, 杨水涁, 无机化学学报, 2019, 35,1805 .)

[43] Pizarro, J.; Flores, E.; Jimenez, V.; Maldonado, T.; Saitz, C.; Vega, A.; Godoy, F.; Segura, R. Sens. Actuators, B 2019, 281, 115.

[44] Xu, W.-N. M.S. Thesis, Shandong Normal Universiy, Jinan, 2008 (in Chinese). (徐伟娜, 硕士论文, 山东师范大学, 济南, 2008.)

[45] Hu, L. M.S. Thesis, Shandong Normal Universiy, Jinan, 2009 (in Chinese).

(胡玲, 硕士论文, 山东师范大学, 济南, 2009.)

[46] Hong, B.-J. M.S. Thesis, Fujian Normal Universiy, Fuzhou, 2010 (in Chinese).

(洪碧琼, 硕士论文, 福建师范大学, 福州, 2010.)

[47] Zhang, L.-J. M.S. Thesis, Shandong Normal Universiy, Jinan, 2012 (in Chinese) (张丽静，硕士论文，山东师范大学，济南, 2012.)

[48] Dagdevren, M.; Yilmaz, I.; Yucel, B.; Emirik, M. J. Phys. Chem. B 2015, 119, 12464.

[49] Alcay, Y.; Yavuz, O.; Gelir, A.; Atasen, S. K.; Karaoglu, K.; Yucel, B.; Tuzun, N. S.; Yilmaz, I. J. Organomet. Chem. 2018, 868, 131.

[50] Flores, E.; Pizarro, J.; Godoy, F.; Segura, R.; Gomez, A.; Agurto, N.; Sepulveda, P. Sens. Actuators, B 2017, 251, 433.

[51] Agurto, N.; Silva, C. P.; Jara, G. S.; Maldonado, T.; Flores, E.; Morales, C. F.; Oliver, A.; Godoy, F.; Pavez, J. Electrochim. Acta 2019, $318,479$.

[52] Ferreira, J. F.; Bagatin, I. A. Spectrochim. Acta, Part A 2018, 189, 44.

[53] Toyama, M.; Fujii, Y.; Endo, M. Inorg. Chim. Acta 2019, 486, 304.

[54] Lukasik, N.; Chojnacki, J.; Luboch, E.; Okuiewski, A.; Wagner-Wysiecka, E. J. Photochem. Photobiol., A 2020, 390, 112307.

[55] Wang, X.-B.; Xiong, H.-J.; Wu, S.-S.; Geng, Z.-R.; Wang, Z.-L. Chin. J. Inorg. Chem. 2020, 36, 1035 (in Chinese). (王小波，熊慧娟，吴莎莎，耿志荣，王志林，无机化学学报， 2020, 36, 1035.)

[56] Parthiban, C.; Elango, K. P. Spectrochim. Acta, Part A 2017, 174, 147.

[57] Moshikur, R. M.; Chowdhury, M. R. Wakabayashi, R.; Tahara, Y.; Kamiya, N.; Moniruzzaman, M.; Goto, M. J. Mol. Liq. 2020, 299, 112166.

[58] Wu, F.-H.; Yang, J.-Q.; Xu, F.; Dong, T.-Y.; Chen, C.; Chu, X.-P. Anal. Sci. 2019, 35, 239 (in Chinese).

(吴芳辉, 杨俊卿, 徐帆, 董天涯, 陈晨, 储心萍, 分析科学学报, 2019, 35, 239.)

[59] Huang, Y.-J.; Lin, J.-S.; Zhang, W.-K.; Zhang, B.-G.; Sun, Q.-Z. Inorg. Chem. Commun. 2019, 105, 129.

[60] Dewangan, S.; Barik, T.; Parida, R.; Mawatwal, S.; Dhiman, R.; Giri, S.; Chatterjee, S. J. Organomet. Chem. 2019, 904, 120999.

[61] Feng, W.-H.; Qiao, C.-J.; Ran, C.-L.; Du, W.; Xu, Y.; Fan, Y.-T. Chin. J. Synth. Chem. 2010, 18, 429 (in Chinese). (冯文浩, 乔纯杰，由春玲，杜薇，徐琰，栎耀亭，合成化学， 2010, 18, 429.)

[62] Devaraj, S.; Elanchezhian, V. S.; Kandaswamy, M. Inorg. Chem. Commun. 2011, 14, 1596.

[63] Uahengo, V.; Xiong, B.; Zhao, P.-P.; Zhang, Y.; Cai, P.; Hu, K.; Cheng, G.-Z. Sens. Actuators, B 2014, 190, 937.

[64] Huang, M.; Lou, Z.-W.; Peng, X.-Q.; He, H.-P.; Zhang, X.-H.; Wang, S.-F. Chin. J. Org. Chem. 2015, 35, 1966 (in Chinese). (黄敏, 娄兆文, 彭小倩, 何汉平, 张修华, 王升富, 有机化学, 2015, 35, 1966.)

[65] Qi, S. M.S. Thesis, Shanghai Institute of Technology, Shanghai, 2016 (in Chinese). (元帅，硕士论文，上海应用技术大学，上海, 2016.)

[66] Li, P.-Q. M.S. Thesis, Hebei University of Science and Technology, Shijiazhuang, 2018 (in Chinese). (李鹏起，硕士论文，河北科技大学，石家庄, 2018.)

[67] Dong, J.-Y. M. S. Thesis, Inner Mongolia University, Hohhot, 2019 (in Chinese) (董均阳，硕士论文，内蒙古大学，呼和浩特, 2019.)

[68] Bao, X.-F.; Cao, X.-W.; Nie, X.-M.; Xu, Y.; Cuo, W.-H.; Zhou, B.-J.; Zhang, L.; Liao, H.; Pang, T. Sens. Actuators, B 2015, 208, 54.

[69] Mathivanan, M.; Tharmalingam, B.; Mani, K. S.; Thiagarajan, V.; Murugesapandian, B. Spectrochim. Acta, Part A 2020, 234, 118235.

[70] Guo, X.-L.; Li, J.; Li, X.; Guo, L.-L.; Zhao, L.-P.; Hou, X.-F. Chem. Reagents 2020, 42, 976 (in Chinese)

(郭心灵, 李静, 李玄, 郭否否, 赵丽平, 侯旭峰, 化学试剂, 2020, 42, 976.)

[71] Tong, L.; Sun, S.-H.; Qiao, M.; Fan, J.; Ding, L.-P. J. Photochem. Photobiol., A 2019, 374, 131 . 
[72] Li, C.-T.; Wang, M.-M.; Zhu, Q.; Cao, Q.-Y. Chin. J. Org. Chem. 2017, 37, 1443 (in Chinese) (李春涛，王蒙蒙，朱倩，曹迁永，有机化学, 2017, 37, 1443.)

[73] Zhao, X.-F.; Cao, Q.-Y.; Lu, X.; Yang, Z.-Y.; Tang, J.-C. Acta Chim Sinica 2012, 70, 838 (in Chinese). (赵小芳, 曹迁永, 卢金鍂, 杨震宇, 唐建成, 化学学报, 2012, 70, 838.)

[74] Wang, J.-C.; Wu, X.-F.; Jiao, X.-L.; Wang, M. Chin. J. Synth. Chem. 2014, 22, 174 (in Chinese). (王健春, 邬孝芳, 焦晓兰, 王梦, 合成化学, 2014, 22, 174.)

[75] Arivazhagan, C.; Borthakur, R.; Ghosh. S. Organometallics 2015, 34, 1147.

[76] Fang, Y.; Zhou, Y.; Rui, Q.-Q.; Yao, C. Organometallics 2015, 34, 2962.

[77] Teng, Q.; Liu, Y.-F.; Hu, J.-F.; Chai, H.; Li, K.-F.; Zhang, H. J. Tetrahedron 2016, 72, 3890.

[78] Liu, Y.-F.; Teng, Q.; Hu, J.-F.; Sun, R.-F.; Zhang, H. Sens. Actuator, $B$ 2016, 234, 680 .

[79] Liu, Y.-F.; Hu, J.-F.; Teng, Q.; Zhang, H. Sens. Actuators, B 2017, $238,166$.

[80] Zhou, Y.-Y.; Cao, Y.; Cong, G.-D.; Zhang, Y.-J.; Zhao, H.-H.; Gao, X.-X.; Zhao, G. Inorg. Chem. Commun. 2018, 96, 170.

[81] Ling, L. Ph.D. Dissertation, Inner Mongolia University, Hohhot, 2019 (in Chinese) (伶俐, 博士论文, 内蒙古大学, 呼和浩特, 2019.)

[82] Zi, J.-X. M.S. Thesis, Inner Mongolia University, Hohhot, 2019 (in Chinese). (訾婧欣，硕士论文，内蒙古大学，呼和浩特, 2019.)

[83] Kim, M.; Mergu, N.; Son, Y.-A. J. Lumin. 2018, 204, 244.

[84] Wang, N.; Arulkumar, M.; Chen, X.-Y.; Wang, B.-W.; Chen, S.-H.; Yao, C.; Wang, Z.-Y. Chin. J. Org. Chem. 2019, 39, 2771 (in Chinese)

(王能, Arulkumar, M, 陈孝云，王柏文，陈思鸿，姚辰，汪朝阳， 有机化学, 2019, 39, 2771.)

[85] Alfonso, M.; Tarraga, A.; Molina, P. Tetrahedron Lett. 2016, 57, 3053 .

[86] Cao, Z.-Y.; Fan, X.; Yang, Z.-Y.; Zhang, X.-B.; Ding, N.-X.-J.; Ding, Y.-B. Sens. Actuators, B 2020, 310, 127855

[87] Xiao, L.-W.; Ren, P.; Jing, X.-M.; Ren, L.-L.; Li, Z.; Dai, F.-C. Chin. J. Org. Chem. 2017, 37, 3085 (in Chinese). (肖立伟, 任萍, 景学敏, 任丽磊, 李政, 戴富才, 有机化学, 2017, 37, 3085.)

[88] Rangasamy, M.; Palaninathan, K. Inorg. Chem. Commun. 2019, 101, 177.

[89] Wang, M.-G.; Peng, J.-X.; Liu, C.-P.; Zheng, M.-Y.; Wang, Y.-X.; Duan, Z.-Y. Chem. Ind. Eng. Prog. 2019, 38, 1941 (in Chinese). (王梅阁，彭家祥，刘成鹏，郑美玉，王雅萱，段中余，化工进展，
2019, 38, 1941.)

[90] Bhatta, S. R.; Pal, A.; Sarangi, U. K.; Thakur, A. Inorg. Chim. Acta 2019, 498, 119097.

[91] Shi, L.; Song, W.; Li, Y.; Li, D.-W.; Swanick, K. N.; Ding, Z.-F.; Long, Y.-T. J. Talanta 2011, 84, 900.

[92] Alfonso, M.; Tarraga, A.; Molina, P. J. Org. Chem. 2011, 76, 939.

[93] Alfonso, M.; Espinosa, A.; Tarraga, A.; Molina, P. Org. Lett. 2011, 13, 2078.

[94] Alfonso, M.; Tarraga, A.; Molina, P. J. Inorg. Chem. 2013, 52, 7487.

[95] Thakur, A.; Ghosh, S. Organometallics 2012, 31, 819.

[96] Sathyaraj, G.; Muthamilselvan, D.; Kiruthika, M.; Weyhermuller, T.; Nair, B. U. J. Organomet. Chem. 2012, 716, 150.

[97] Romero, T.; Orenes, R. A.; Tarraga, A.; Molina, P. Organometallics 2013, 32, 5740.

[98] Kumar, C. K.; Trivedi, R.; Kumar, K. R.; Giribabu, L.; Sridhar, B. Eur. J. Inorg. Chem. 2013, 35, 6019 .

[99] Kumar, C. K.; Trivedi, R.; Giribabu, L.; Niceditha, S.; Bhanuprakash, K.; Sridhar, B. J. Organomet. Chem. 2015, 780, 20.

[100] Thakur, A.; Mandal, D.; Ghosh, S. J. Anal. Chem. 2013, 85, 1665.

[101] Wang, Z.-C.; Dai, B.-N.; Qiu, J.-F.; Cao, Q.-Y.; Ge, J.-Z. Chin. J. Org. Chem. 2015, 35, 2383 (in Chinese). (王智成，戴博娜，丘继芳，曹迁永，葛金柱，有机化学，2015, 35, 2383.)

[102] Bhatta, S. R.; Bheemireddy, V.; Vijaykumar, G.; Debnath, S.; Thakur, A. Organometallics 2017, 36, 2141.

[103] Wu, X.-F.; Wu, P.; Li, J.-Y.; Lu, Q.; Wang, J.-C. Chin. J. Org. Chem. 2017, 37, 1412 (in Chinese)

(乌孝芳, 武沛, 李敬瑜, 陆婧, 王健春, 有机化学, 2017, 37, 1412.)

[104] Ren, Y.-P.; Liu, X.; Wang, R.; Zhou, Y.-Q.; Li, B.; Xu, Y.; Song, M.-P. Chin. J. Org. Chem. 2017, 37, 110 (in Chinese). (任亚平, 刘絮, 王瑞, 周元清, 李标, 徐琰, 宋毛平, 有机化学, 2017, 37, 110.)

[105] Hou, J.-N. M.S. Thesis, Inner Mongolia University of Technology, Hohhot, 2018 (in Chinese). (候静娜, 硕士论文, 内蒙古工业大学, 呼和浩特, 2018.)

[106] Sun, Q. M.S. Thesis, Inner Mongolia University, Hohhot, 2018 (in Chinese).

(孙琦，硕士论文，内蒙古大学，呼和浩特, 2018.)

[107] Jia, H.-J.; Han, L.-M.; Zhu, N.; Gao, Y.-Y.; Wang, Y.-Q.; Suo, Q.-L. Chin. J. Org. Chem. 2019, 39, 1753 (in Chinese) (贾慧劼, 韩利民，竺宁，高媛媛，王亚琦，索全伶，有机化学， 2019, 39, 1753.)

[108] Xu, J.-W.; Yang, T.-Q.; Baigude, H.; Zhao, H.-Y. Spectrochim. Acta, Part $A$ 2020, 229, 117880 . 